\title{
An Analysis of Fuel Shares in the Industrial Sector
}

J. M. Roop

D. B. Belzer

June 1986

Prepared for the U.S. Department of Energy under Contract DE-AC06-76RLO 1830

Pacific Northwest Laboratory Operated for the U.S. Department of Energy by Battelle Memorial Institute 


\section{DISCLAIMER}

This report was prepared as an account of work sponsored by an agency of the United States Government. Neither the United States Government nor any agency thereof, nor any of their employees, makes any warranty, express or implied, or assumes any legal liability or responsibility for the accuracy, completeness, or usefulness of any information, apparatus, product, or process disclosed, or represents that its use would not infringe privately owned rights. Reference herein to any specific commercial product, process, or service by trade name, trademark, manufacturer, or otherwise, does not necessarily constitute or imply its endorsement, recommendation, or favoring by the United States Government or any agency thereof. The views and opinions of authors expressed herein do not necessarily state or reflect those of the United States Government or any agency thereof.

\section{PACIFIC NORTHWEST LABORATORY operated by \\ BATTELLE \\ for the \\ UNITED STATES DEPARTMENT OF ENERGY \\ under Contract DE-AC06-76RLO 1830}

\begin{tabular}{|c|c|}
\hline \multicolumn{2}{|c|}{ Printed in the United States of America } \\
\hline \multicolumn{2}{|c|}{ Available from } \\
\hline \multicolumn{2}{|c|}{ National Technical Information Service } \\
\hline \multicolumn{2}{|c|}{ United States Department of Commerce } \\
\hline \multirow{2}{*}{\multicolumn{2}{|c|}{$\begin{array}{l}5285 \text { Port Royal Road } \\
\text { Springfield, Virginia } 22161\end{array}$}} \\
\hline & \\
\hline \multirow{2}{*}{\multicolumn{2}{|c|}{$\begin{array}{l}\text { NTIS Price Codes } \\
\text { Microfiche A01 }\end{array}$}} \\
\hline & \\
\hline \multicolumn{2}{|c|}{ Printed Copy } \\
\hline & Price \\
\hline Pages & Codes \\
\hline $001-025$ & A02 \\
\hline $026-050$ & A03 \\
\hline $051-075$ & A04 \\
\hline $076-100$ & A05 \\
\hline $101-125$ & A06 \\
\hline $126-150$ & A07 \\
\hline $151-175$ & $\mathrm{~A} 0 \mathrm{~B}$ \\
\hline $176-200$ & A09 \\
\hline $201-225$ & A010 \\
\hline $226-250$ & A011 \\
\hline $251-275$ & A012 \\
\hline $276-300$ & $\mathrm{~A} 013$ \\
\hline
\end{tabular}


PNL-5796

UC-98

AN ANALYSIS OF FUEL SHARES

IN THE INDUSTRIAL SECTOR

J. M. Roop

D. B. Belzer

June 1986

Prepared for

the U.S. Department of Energy

under Contract DE-AC06-76RL0 1830

Pacific Northwest Laboratory

Richland, Washington 99352 



\section{SUMMARY}

This report is one of two conducted by Pacific Northwest Laboratory (PNL) for the Office of Policy Integration, U. S. Department of Energy, to analyze and project fuel shares in the industrial and residential sectors. These studies have three purposes: 1) to describe how fuel shares have changed over time; 2) to determine what factors are important in promoting fuel share changes; and 3) to project fue1 shares to the year 1995. These three major objectives are applied to the industrial sector in this report.

A general characterization of changes in fuel shares of four fuel types--coal, natural gas, $0 i 1$ and electricity--for the industrial sector is as follows. Coal as a major fuel source declined rapidly from 1958 to the early 1970s, with oil and natural gas substituting for coal. Coal's share of total fuels stabilized after the oil price shock of 1972-1973, and increased after the 1979 price shock. In the period since 1973, most industries and the industrial sector as a whole appear to freely substitute natural gas for oil, and vice versa. Throughout the period 1958-1981, the share of electricity as a fuel increased. These observations are derived from analyzing the fuel share patterns of more than 20 industries over the 24-year period 1958 to 1981 .

An examination of the factors that might explain why this substitution has occurred suggests the following. Factors that contributed to fuel substitution varied among industries, but generally the decline of coal can be explained by the inconvenience of handling the fuel, environmental considerations, and technical requirements for the heat produced by cleaner fuels. The increase in electricity follows from its special uses and the ease with which it can be controled. The free substitution of oil and gas follows from availability, price considerations, and technical factors. In the course of this study, it became clear that treating the industrial sector as a whole obscured some of the industry-specific changes that have taken place over the last 25 years.

The projection of fuel share forecasts for the industrial sector as a whole is based on forecasts of energy prices developed by the Energy Information Agency's (EIA) Annual Energy Review 1984. These projections, along with the most recent historical period, are shown in Figure S.1. 


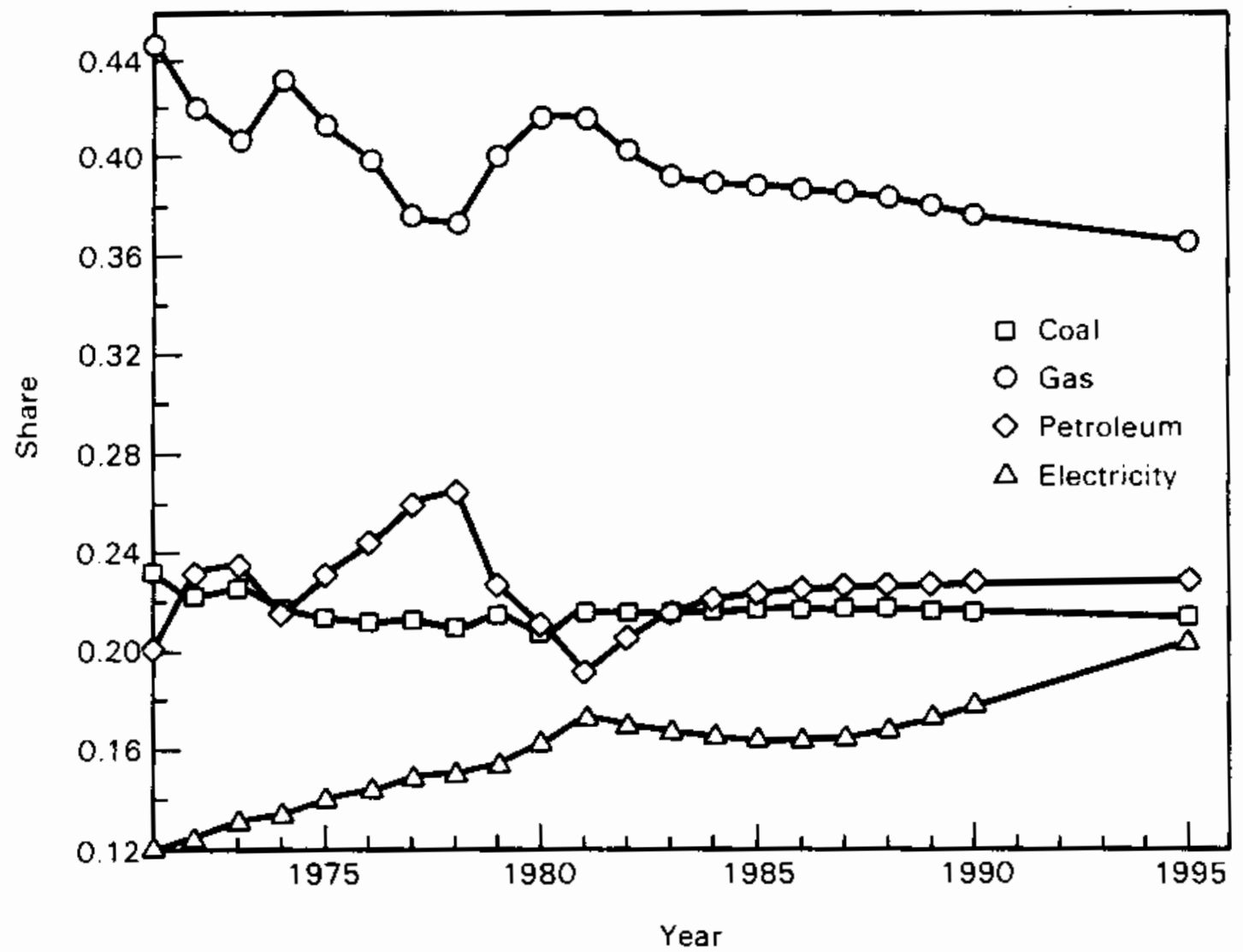

FIGURE S.1 Industrial Sector Fuel Shares, History and Projections to 1995

Given only moderate increases in oil prices throughout the rest of the decade, the share accounted for by petroleum rebounds from its 1981 low to reach nearly the level observed in 1979. Increases in gas prices relative to both $0 i 1$ and electricity help to diminish the fraction of energy use from gas. The natural gas share is projected to fall to about 36 percent, as compared to a peak of 42 percent in 1980 and 1981 . Electricity continues its historical upward trend as a fraction of total industrial energy use. By 1995 it is projected to be over 20 percent as compared to 17 percent in 1981 .

Although the simple forecasting method provides reasonable historical tracking and projections of future fuel shares for the industrial sector as a whole, there are a number of areas in which the methodology could be improved. This becomes evident when the method is applied to specific industries. Improvements could be obtained from a more rigorous derivation of the projection methodology from the economic theory of production. The report describes in general terms how this approach might be followed in future research. 


\section{ACKNOWLEDGEMENTS}

The authors wish to acknowledge the able assistance received from a number of individuals here at Pacific Northwest Laboratory (PNL), and at the Department of Energy (DOE). At PNL we especially want to acknowledge C. R. Tierney and A. L. Dittmer, who provided computer support and did the initial graphics. We have also benefitted from the helpful comments of R. J. Moe and R. M. Scheer. A number of conversations with B. MCNutt, the DOE contract monitor, have helped to narrow the focus and better define the scope of this report. We want to also thank $G$. A. Robertson for secretarial ajd. 
. 


\section{CONTENTS}

SUMMARY

ACKNOWLEDGEMENTS

1.0 INTRODUCTION

1.1 OBJECTIVES OF THE STUDY



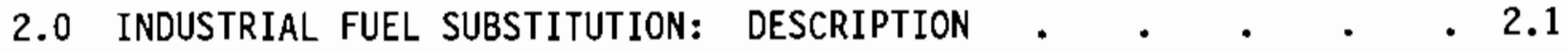



2.1.1 Private Economy . . . . . . . . . 2.5

2.1.2 Industrial Sector . . . . . . . . . 2.6

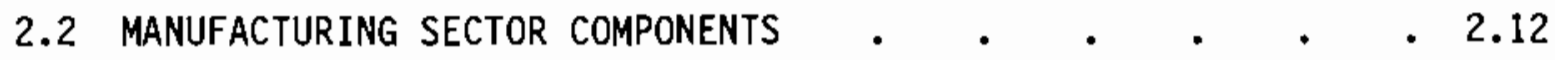

2.2.1 Fuel Share Patterns . . . . . . . 2.12

2.2.2 Exceptional Industries . . . . . . . . 2.16

2.3 GENERAL CHARACTERIZATION OF TRENDS . . . . . . . . 2.23

3.0 FACTORS INFLUENCING INDUSTRIAL FUEL SUBSTITUTION $\quad \cdot \quad \cdot \quad \cdot \quad$ • 3.1

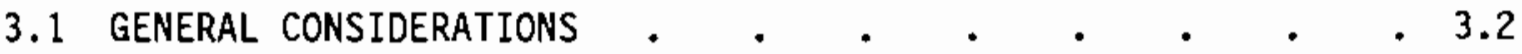

3.1.1 Technologieal Factors . . . . . . . 3.3

3.1 .2 Legal and Institutional Factors . . . . . 3.4

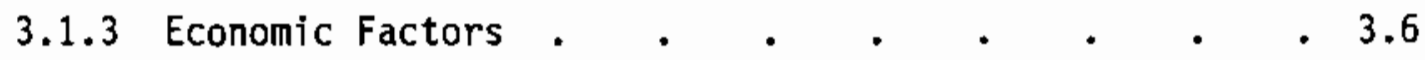

3.1 .4 Sumnary . $. \quad . \quad . \quad . \quad . \quad . \quad . \quad . \quad 3.10$

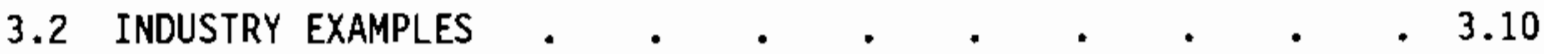

3.2 .1 Cement $. \quad . \quad . \quad . \quad . \quad . \quad . \quad$. 3.11

3.2.2 Primary Iron and Steel . . . . . . . 3.15

3.2 .3 Other Industries . . . . . . . . . 3.22

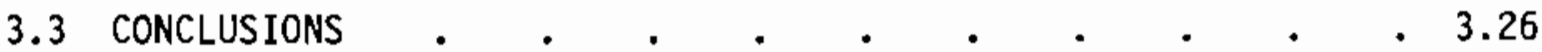


4.0 PROJECTIONS OF FUEL SHARE TO 1995.

4.1 APPROACH

4.2 EMPIRICAL RESULTS

4.2.1 Results for the Industrial Sector

4.2.2 Results for Selected Industries.

4.3 FUEL SHARES PROJECTIONS .

4.3.1 Base Case Projections

4.3.2 A] ternative Projections

4.4 ALTERNATIVE APPROACHES BASED ON PRODUCTION THEORY .

5.0 CONCLUSIONS AND RECOMMENDATIONS

5.1 CONCLUSIONS

5.2 RECOMMENDATIONS

REFERENCES
- 4.1

- 4.1

. 4.3

- 4.3

- 4.8

. 4.11

. 4.11

. 4.15

. 4.15

- 5.1

- 5.1

- 5.2

- R. 1

viii 


\section{$\underline{\text { TABLES }}$}

2.1 Energy Products and Functional Uses In National Energy Accounts . 2.2

2.2 Definitions of Industry Aggregates . . . . . . . . 2.4

4.1 Coefficient Estimation: Aggregate Industrial Sector . • . 4.4

4.2 Annual Gas Deliveries and Curtailments, U. S. Totals, SIC's 20-39 4.7

4.3 Coefficient Estimation: Textiles . . . . . . . . 4.8

4.4 Coefficient Estimation: Hydraulic Cement . . . . . . 4.9

4.5 Alternative Price and Fuel Share Projections . . . . . 4.13 


\section{FIGURES}

S.1 Industrial Sector Fuel Shares, History and Projections to 1995 . iv

2.1 Fuel Shares for Total Private Economy . $\quad$ • $\quad$ • $\quad$ • 2.5

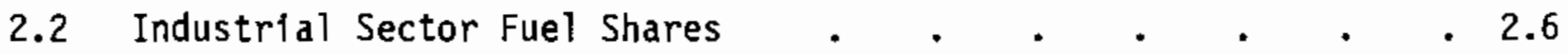

2.3 Agriculture and Services - Fuel Shares . . . . . . 2.7

2.4 Petroleum and Natural Gas Mining - Fuel Shares . . . . 2.9

2.5 Other Mining - Fuel Shares . . . . . . . . . . 2.9

2.6 Construction - Fuel Shares . . . . . . . . . 2.10

2.7 Manufacturing - Fuel Shares . . . . . . . . . 2.11

2.8 Fuel Shares for Industrial Sector and for Manufacturing * . 2.11

2.9 Coal and Natural Gas Shares, 1958, 1972, and 1981, All Industries 2.14

2.10 Petroleum and Electricity Shares, 1958, 1972 and 1981,

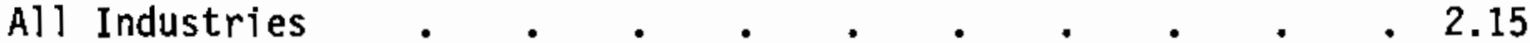

2.11 Textiles - Fuel Shares . . . . . . . . . . 2.17

2.12 Industrial Organic and Inorganic Chemicals - Fuel Shares $\quad$ : 2.18

2.13 Petroleum Refining - Fuel Shares . . . . . . . . 2.20

2.14 Hydraulic Cement - Fuel Shares . . . . . . . . . . 2.21



3.1 Efficiencies of Pyroprocessing of Cement at Different Plants,

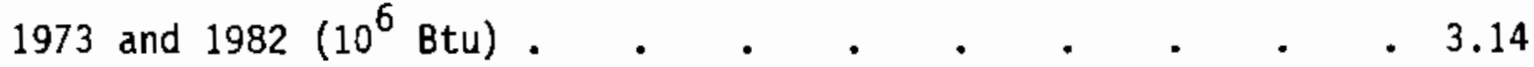

4.1 Predicted and Actual Shares by Fuel, Total Industrial Sector,



4.2 Relative Prices by Fuel Type, 1971-1981 . . . . . . . 4.6

4.3 Predicted and Actual Shares by Fuel for Textfles, 1971-1981 . 4.10

4.4 Predicted and Actual Shares by Fuel for Cement, 1971-1981 • . 4.12

4.5 Baseline Projections of Industrial Sector Fuel Shares . . . 4.13 


\subsection{INTRODUCTION}

The fuel purchased for heat and power in the industrial sector has changed dramatically over the last 25 years. Natural gas has replaced coal as the most widely used fuel, coal use has been reduced by nearly 40 percent, and electricity's share has more than doubled. The purpose of this report is to discuss these changing fuel shares in the industrial sector, to enumerate some of the reasons for the changes that have occurred over time, and to show the variety of experience that is summarized by the industrial sector as a whole.

Knowing how fuel shares have changed over time and why these changes have happened is valuable for several reasons. Policy decisions invariably alter the environment in which the choice of fuels is made and thus affect the outcome. An analysis of the past helps one to understand what in this changing environment may have given rise to fuel substitution and how past policy may have had an effect. If some fuels substitute more readily than other fuels, policy can be structured to reflect that fact. And many policy decisions are responses to events such as the OPEC oil shocks, the initial effect of which was a sharp change in the relative price of one fuel. Thus a description of fuel share changes over time, and a discussion of the factors that cause this substitution is useful background for policy analysis.

This description relies heavily on the National Energy Accounts (NEA) described in Faucett (1984). The NEA provide the only publicly available set of time-series data on energy use by industry that can be aggregated to total energy use data available from the purchased heat and power survey of the Census Bureau's Annual Survey of Manufactures [U. S. Department of Commerce (DOC), 1981]. By including uses other than heat and power, the NEA can be aggregated to total energy use (DOE 1984). This report primarily considers the energy

used by industry for heat and power; we have assumed that energy purchased for other use would not be used for heat and power, i.e., feedstocks are not substitutable for coal, natural gas or oil in steam production.

The fuels from the NEA have been aggregated into four categories--coal, natural gas, petroleum products and electricity. The energy content of these fuels is measured in Btu, with electricity evaluated at delivery heat con- 
tent--3412 Btu/kwh. This seems an appropriate measure for examining fue 1 substitution, although we recognize that it is an inappropriate measure if the interest is total primary energy use. The description and analysis has been limited to these four fuels, although other substitution possibilities exist. Some industries both produce and consume energy products; biomass in pulp and paper and cogenerated electricity in a number of industries are examples that come readily to mind. In order to provide a generic treatment for all industries, these energy sources have been excluded from consideration in this report except when the focus is on a particular industry and has some bearing on the choice of purchased fuels.

It is clear that fuel use is contingent on the set of equipment in place. There is some flexibility in the use of particular fuels for, say, a given boiler, but typically, a given stock of equipment requires fixed energy inputs. In this study no attempt has been made to differentiate fuel uses that result from differences in the capital equipment used to convert that fuel into an energy service. From the perspective of the plant operator, the relevant consideration may well be the energy service delivered to a particular process, not the fuel that provides that service. The cost of the capital that provides an energy service, in combination with any particular fuel, will also affect the choice of fuels. An electric furnace for glass making will typically have a higher capital cost and a shorter life span than a similar furnace that uses natural gas; the life-cycle costs of these two options will influence the share of gas and electricity in glass making over time. There are instances where these capital costs have been measured and associated with fuel use (Reister and Devine, 1981).

In this study, we have not attempted to address the interaction between such factors as the type of equipment in place or the cost of capital and fuel use. Rather, the emphasis has been placed on a description of what actualiy happened, and on explanations of why fuel substitution occurred. The analytical portion of this study puts a high premium on simplicity. In the analysis, reliance has been placed on fuel shares calculated on a Btu basis; the prices of these fuels, again weighted simply by their Btu content; and other readily available data. 
The terminology used in this report needs some clarification. The focus of the analysis is changes in fuel shares over time. As these shares change, so too does the relative amount of fuels used for heat and power. Therefore, the phrase "fuel share change" and "substitution" are used interchangeably. We have tried to avoid the phrase "fuel switching" even though such a switch would be revealed as a share change as well. But switching has the connotation of occurring immediately, and is applied typically to a particular piece of equipment. Since the data used in this study are annual and since the focus is primarily at the industry level, we anlayze fuel share changes rather than fuel switching.

\subsection{OBJECTIVES OF THE STUDY}

The objectives of this report are threefold. The first is to describe the fuel substitution that has occurred in the industrial sector of the economy over the past several years, as measured by share changes. This description relies on fuel share data calculated from the NEA which extend from 1958 to 1981. The industrial sector is comprised of agriculture, mining, construction and manufacturing. The information from the NEA allows each of these components of the industrial sector to be examined.

The second objective of this. report is to understand why substitution among fuels has occurred in the industrial sector. Fuel share changes may occur because of economic reasons, because of legal requirements, or because of technical advantages that result from changing from one fuel to another. The second objective is achieved by first examining these reasons, then applying them to specific industries. The variety of industrial experience is shown here as several different manufacturing industries are examined. These industry aggregates are primarily at the 2-digit Standard Industrial Classification (SIC), but in some cases are broader (machinery) or more narrowly defined (primary aluminum).

The third objective of this report is to develop a method of projecting shares of energy consumption by fuel type for the industrial sector. The knowledge gained in pursuit of the second objective carries over to aid in achieving this objective. A simple approach is developed that focuses on the relationship of fuel shares and relative fuel prices. Other factors such as 
capacity utilization and variables representing gas curtailments were tested and included where statistically significant. The major advantage of this approach is its simplicity and its minimal data requirements. But there are a number of drawbacks to this approach, and these became evident when the method is applied on an industry-by-industry basis.

\subsection{STRUCTURE OF THE REPORT.}

This report is organized into six sections inciuding this introduction. The next section provides an historical description of the changing pattern of fuel shares for the economy as a whole, for the industrial sector, and then for the major industry aggregates that comprise the industrial sector: agriculture, two mining sectors, construction and manufacturing. Section 2.0 also discusses some of the industries within manufacturing that are identified for this report. The third section then examines factors that might account for fuel substitution--economic, legal and technical. Once these factors are identified, they are applied to individual industries within the manufacturing sector. In Section 4.0, a method is developed to project fuel shares, The projections require forecasts of total energy use and relative fuel prices. Fuel shares are then projected to 1995, for the industrial sector as a whole, using fuel prices forecasts from the Annual Energy Outlook (DOE, 1985). The forecast method is applied at the detailed industry level with mixed success. Section 4.0 closes with a discussion of how the economic theory of production could be used to improve the method of forecasting.

Section 5.0 concludes the report by summarizing the findings of the fuel shares analysis, discussing the advantages and disadvantages of the forecasting method, and recommending alternative methods for examining fuel substitution. The final section provides reference to the cited publications. 


\subsection{INDUSTRIAL FUEL SUBSTITUTION: DESCRIPIION}

The major objective of this section is to describe the changes in fuel shares that have occurred in the industrial sector over time. The industrial sector is comprised of manufacturing, agriculture, mining and construction. Each of these may exhibit different patterns of fuel substitution, so the section begins by describing fuel use in these industry aggregates. Moreover, manufacturing is comprised of 20 2-digit industries, as organized in the Standard Industrial Classification (SIC). Each of these 2-digit SICs can be further disaggregated into 3 - and 4-digit industries which may show patterns of fuel substitution that are quite different within 2-digit classifications. The second section of this description explains how manufacturing has been classified and illustrates the diversity of fuel substitution patterns. In the final section, this information is sumarized into a general characterization of fuel substitution trends.

Before beginning the task of describing fuel substitution in the industrial sector, there are two procedural items that need to be briefly covered. The first of these is the data source, the second is the method of organizing the data. The major data source used in this report is the National Energy Accounts (NEA) (Faucett, 1984), developed Jointly by the Department of Commerce and the Department of Energy. This data base allocates energy use by fuel types to individual industries based on source information from the Department of Energy and use information derived from the Annual Survey of Manufactures (e. g., U. S. Department of Commerce, 1981) or the Census enumeration every five years (e.g., U. S. Department of Conmerce, 1980). These data have been aggregated both by fuel types and by industries for this report.

Fuel use in the industrial sector has been organized into four fuel types: coal, natural gas, petroleum products and electricity. Table 2.1 shows the energy products and functional uses of fuels as reported in the NEA. For an analysis of fuel substitution, only fuel purchased for heat and power is included; energy losses and other uses such as fossil-based feedstocks, fuels that are by-products of the production process (e.g., still gas in petroleum refining), fuels derived from wastes (e.g., biomass in pulp production) are 
TABLE 2.1 Energy Products and Functional Uses in National Energy Accounts

NEA

CODE

ENERGY PRODUCT

PRIMARY ENERGY PRODUCTS

110

120

130

140

150

160

180

221

222

223

231

232

233

234

235

236

237

238

241

242

243

250

Crude $0 i 1$ (including lease condensate)

Natural gas -- wet

Coal

Nuclear power

Water power

Geothermal power

Wood for fuel

Natural Gas (dry, from gas wells)

CONVERTED HYDROCARBONS

Light Hydrocarbon Gases

211

Ethane and ethylene

Liquid petroleum and refinery gases (propane, butane, isobutane and propane-butane mixtures)

Natural Gas and Similar Products

Natural gas (dry, from gas plants) and other utility gases

Still gas

Coke oven gas

Gasoline and Naphthas

Motor gasoline

Aviation gasoline

Special naphthas

Naphtha 400 and other petrochemical feedstocks

Naphtha type jet fuels

Natura1 gasoline and isopentane

Plant condensate

other natural gas liquids

Distallate Fuel 0ils

Kerosine jet fuel

Kerosine, except kerosine jet fuel

Distillate, except kerosine

Residual Fuel 0ils

27.0

Unsaturated light hydrocarbons

271 Crude light oil (from coal) 
IABLE 2.1 (Continued)

281

282

283

284

291

292

293

410

999

NEA

CODE

10

31

32

33

34

35

36

37

38

39

40

50

60

80

90

99 0ther Petroleum Products Lubricating oils and greases

Aspha1t, road tar, road oil

Miscellaneous petroleum products

Unfinished oils

Coal Derivatives and Petroleum Coke

Coke and Breeze

other coal derivatives

Crude coal tar

ELECTRICITY

Electricity

Conversion Losses

FUNCTIONAL USE

Heat and power

Transportation

Passenger highway vehicles, exc. buses

Buses

Trucks

Aircraft

Railroad vehicles

Pipeline equipment (stationary)

Waterborne vehicles

Transportation fuel -- off the road

Communications transmission

Energy materials -- inputs to energy conversion process

Energy materials -- inputs to nonenergy activities

Energy losses

Export

Produced and consumed

Unallocated, use unknown

SOURCE: Faucett, 1984, pp. 187, 188. 
excluded from this report. (a) The NEA product codes that are aggregated to the coal category as used in this report are 110, 223, and 291-293. Natural gas is NEA code 221 while electricity is code 410. Petroleum is the sum of a11 converted hydrocarbons not included in the other fuels. The fuel uses are reported in Btu, as if each of the fuels substituted on a Btu-for-Btu basis. Electricity is reported at busbar energy content--3412 Btu/kWh--rather than based on the energy required to produce a kWh (approximately 10,470 Btu). Table 2.2 lists the industries defined for this study and the corresponding NEA industries had they been organized sequentially in Faucett (1984).

TABLE 2.2. Definitions of Industry Aggregates

\begin{tabular}{llc} 
Abbreviation & \multicolumn{1}{c}{ Description } & NEA Industry \\
\cline { 1 - 3 } AG & Agriculture and Services & $1-4$ \\
PNGM & Petroleum and Natual Gas Mining & $10-12$ \\
NEM & Other Mining & $5-9,13,14$ \\
CNST & Construction & $15-17$ \\
& & \\
FOOD & Food and Kindred Products & 21 \\
TEX & Textiles & $23-25$ \\
WOOD & Lumber and Wood Products & $28-30,86$ \\
P\&P & Pulp and Paper Products & $33-35$ \\
ICHEM & Indus, Organic \& Inorganic Chemicals & 37 \\
OCHEM & Other Chemical Products & $18,38-45$ \\
PETR & Petroleum Refining & $46-48$ \\
RUB & Rubber and Miscel laneous Products & 49 \\
GLAS & Glass and Glass Products & 52 \\
CEM & HydrauTic Cement & 53 \\
STON & Stone and Clay Products X Cement & 54 \\
I\&S & Primary Iron and Steel Products & $55-58$ \\
OPM & Other Primary Metals X Aluminum & 60 \\
PAL & Primary Aluminum & 59 \\
FMP & Fabricated Metal Products & $61-65$ \\
MACH & Electricial and Nonelec. Machinery & $66-82$ \\
TREQ & Transportation Equipment & $83-85$ \\
ONM & Other Nondurable Manufacturing & $22,26,27,36,50,51$ \\
ODM & Other Durable Manufacturing & $19,20,31,32,87-89$ \\
ALLO & All Other Private Industry Sectors & $90-120$ \\
&
\end{tabular}

(a) In large measure the increased use of by-products and wastes represents an increase in efficiency. The economizing that this represents will likely operate to increase the fuel share of the most efficiently used fuel, which in most cases is electricity. This fact may account for the secular increase in the share of electricity. 


\subsection{INDUSTRY AGGREGATES}

Although the focus of this report is on the industrial sector, there are other segments of the private economy that also consume energy. The industrial sector includes most of the industries engaged in the production of goods--agriculture, mining, construction and manufacturing--while the remainder of the private economy is primarily engaged in the production of services--communications, transportation, wholesale and retail trade, and other services. In recent years, the non-goods producing sectors of the economy account for a larger fraction of total output than does the industrial sector, but energy use in these sectors is low by comparison. This section will first look briefly at the private economy, then at the industries that comprise the industrial sector.

\subsubsection{Private Economy}

Figure 2.1 shows fuel shares for the total private economy from 1958 through 1981. Over this period, natural gas increased its share from about 34 percent to a peak of 45 percent in 1971; over the subsequent 10 years, the share has fluctuated, but overall has declined to about 42 percent. Electricity has shown a steady increase in its share from about 8 percent in 1958

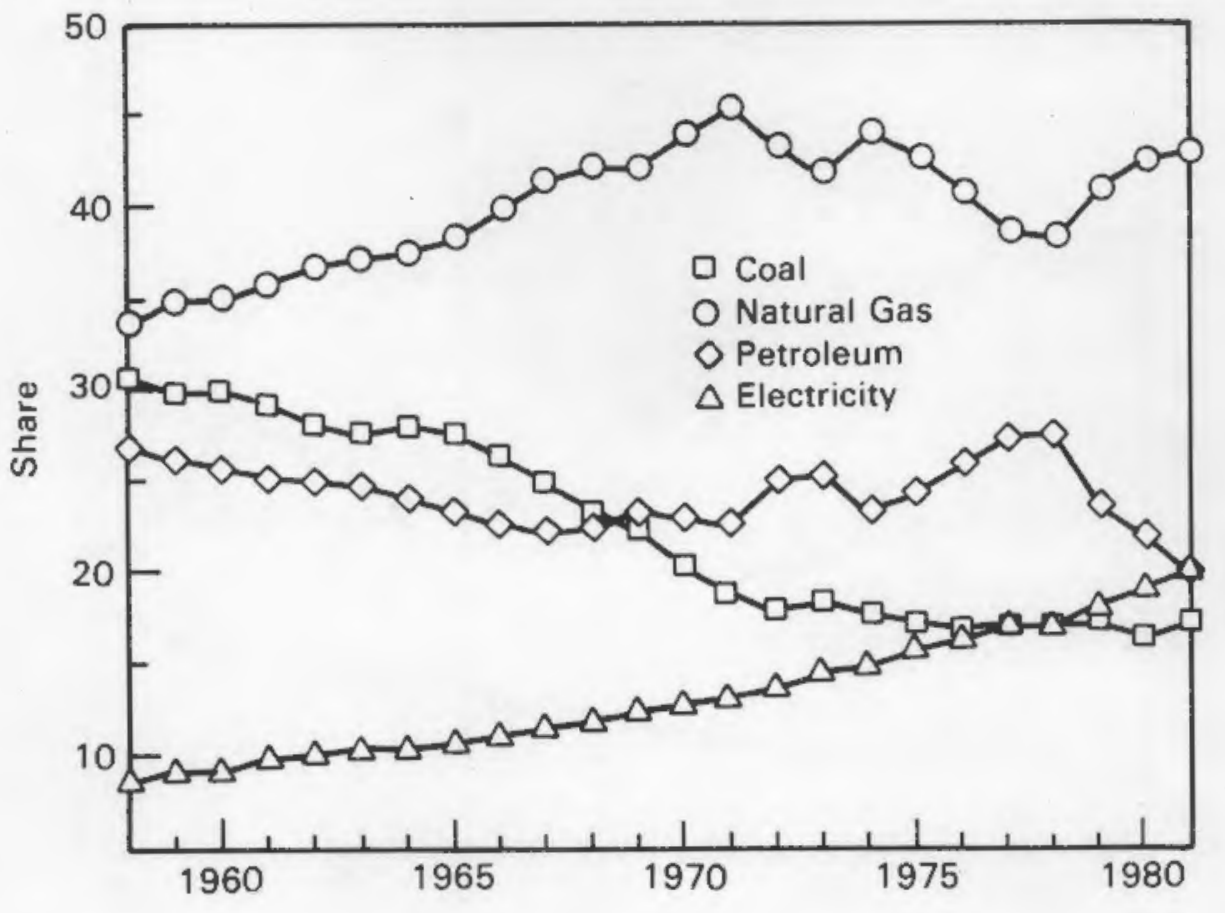

FIGURE 2.1 Fuel Shares for Total Private Economy 
to nearly 20 percent in 1981 . Coal, on the other hand, has shown a steady decline, from more than 30 percent in 1958, to about 17 percent in 1981 . The decline in coal's share appears to have accelerated in the mid 1960s, dropping nearly 10 percentage points from 1965 to 1972. From 1972 through 1981, the share of coal appears to have stabilized. Petroleum, as a percent of total fuel use, declined modestly from 1958 to 1967 , but thereafter appears to mirror the changes in natural gas--when the gas share increases the oil share declines, and vice versa. It is worth noting that these general patterns are often repeated--electricity's share increases steadily, coal's share declines until the early 1970 's, and natural gas and oil shares appear to mirror each other through time.

\subsubsection{Industrial Sector}

Figure 2.2 shows fuel shares in the industrial sector. The pattern of fuel share changes over time is similar to that of the total private economy, with some minor differences. Electricity's share does not increase as rapidly in the industrial sector; it begins the period at about 8 percent, but increases to only 17 percent compared to 20 percent for the total private economy. coal use in the industrial sector declines from about 36 percent to 22 percent

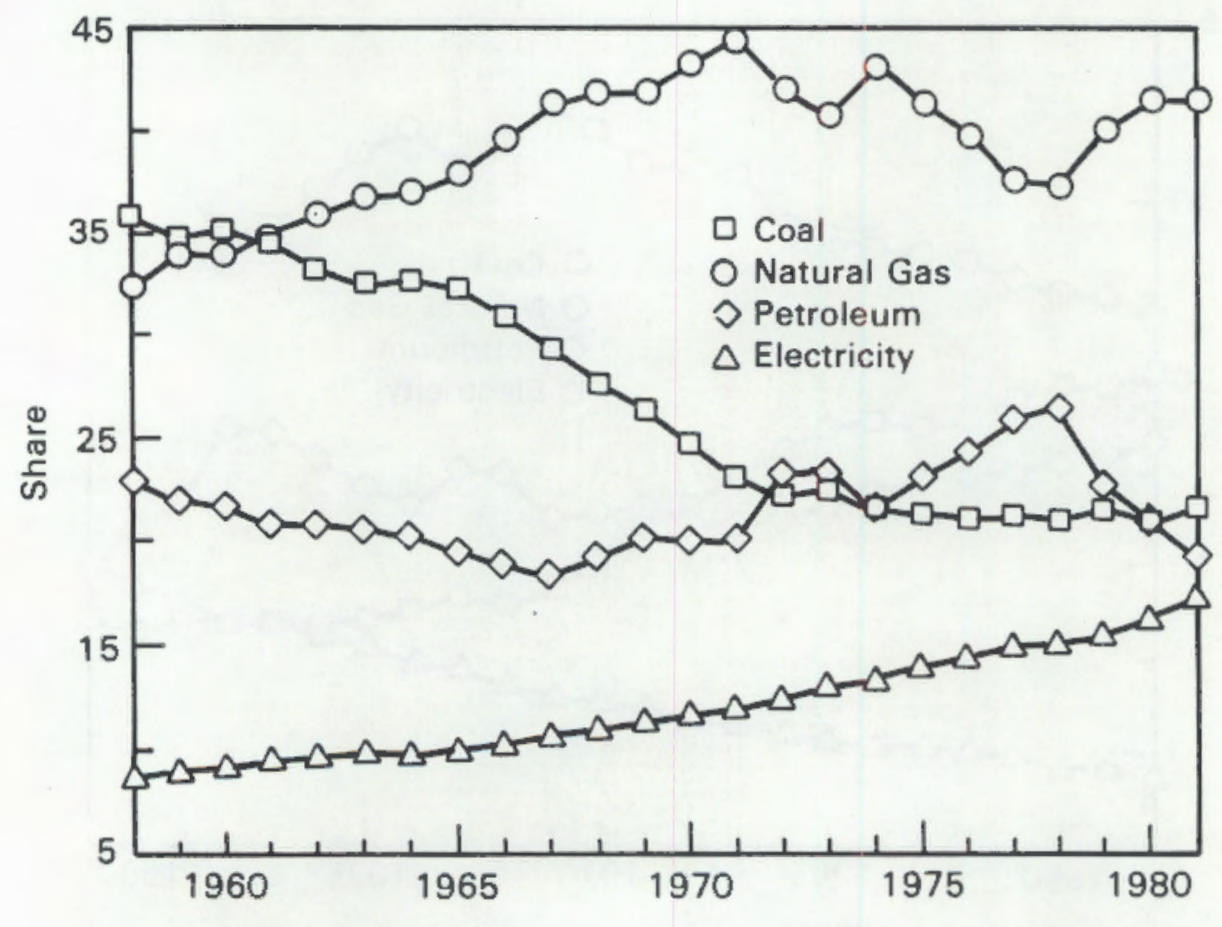

FIGURE 2.2 Industrial Sector Fuel Shares 
in 1981, with a rapid decline from 1965 to 1972 . Once the coal share stabilizes, oil and natural gas movements appear as mirror images, as occurs for the private economy. The trends for the industrial sector, then, are much the same as for the total private economy.

The industrial sector is comprised of agriculture, mining, construction and manufacturing. These components of the industrial sector have been organized into five aggregate sectors: agriculture and services (which includes agriculture, forestry, fisheries and agricultural services such as crop dusting), petroleum and natural gas mining, other mining, construction, and manufacturing. The remainder of this section discusses fuel share movements for these aggregate sectors; the next section disaggregates manufacturing into some of the characteristic industries.

\section{Agriculture and Services}

Figure 2.3 shows the three fuel shares for agriculture and services; coal and petroleum are combined since so little coal is used in this sector. The trends here appear quite different from the industrial sector as a whole. The use of natural gas shows a steady decline from 1958 to 1974, with considerable fluctuations in its share thereafter. Until 1973, petroleum appears

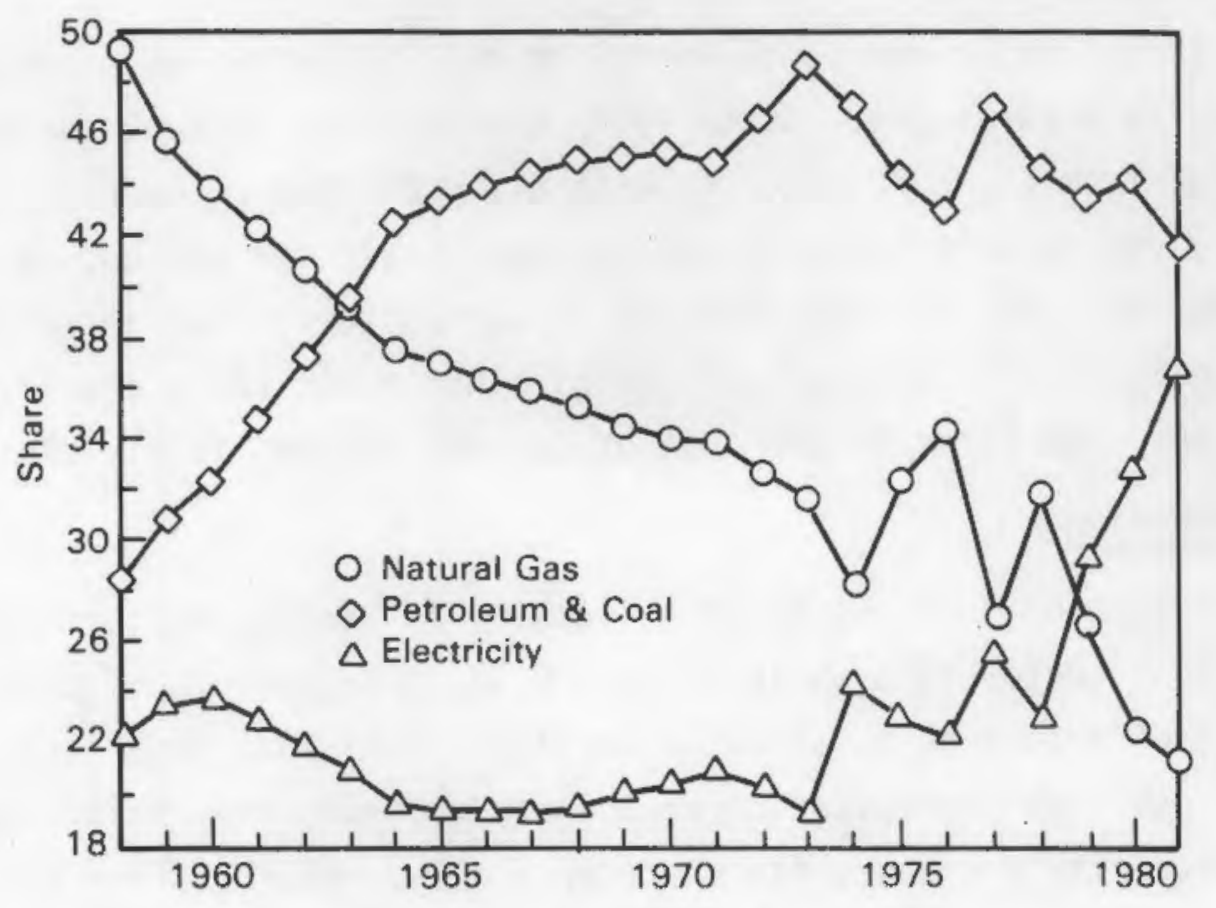

FIGURE 2.3 Agriculture and Services - Fuel Shares 
to substitute for both natural gas and electricity. In the four years from 1974 to 1978, the natural gas share first increases sharply, from 28 to nearly 35 percent, while both oil and electricity shares decline, then drops and rebounds while oil and electricity move diametrically. But in the subsequent years, from 1979 to 1981, electricity appears to substitute for both oil and gas. Are these substitutions possible from a technological point of view?

U. S. Department of Agriculture estimates of energy use for 1981 indicate that there are several technologies that satisfy the same energy service that use different fuels. For example, irrigation consumes about 16 percent of all energy used in the production of crops; it is a major user of natural gas, electricity and petroleum products. Water heating, in dairy operations as an example, could also allow substitution possibilities, as could temperature control (brooding is a major consumer of energy) in some operations. But these technological possibilities probably do not account for all the substitution that appears in Figure 2.3. A possible reason for the sharp increase in electricity's share after 1978 could be a decline in gas and petroleum use as production declined, with the level of electricity use declining less than commensurately.

\section{Petroleum and Natural Gas Mining}

Clearly the major source of energy in this industry, as evident from Figure 2.4, is natural gas. Since 1960, the share of natural gas has varied in the range from 60 to 70 percent, with oil substituting modestly for gas. Electricity use in this industry has increased over the period, as it has in most industries. In this industry, as in agriculture, that increase can be explained primarily by the economizing of other fuels while electricity use, either in absolute terms or per unit of output, remains fairly constant.

\section{other Mining}

The pattern of fuel use in this industry is similar to that shown for the industrial sector as a whole (Figure 2.5). The pattern of the coal share is somewhat different here, since it declines until 1972, increases until 1977, then declines thereafter. For the other fuels, the familiar patterns occur--electricity increases its share generally, while oil and gas shares 


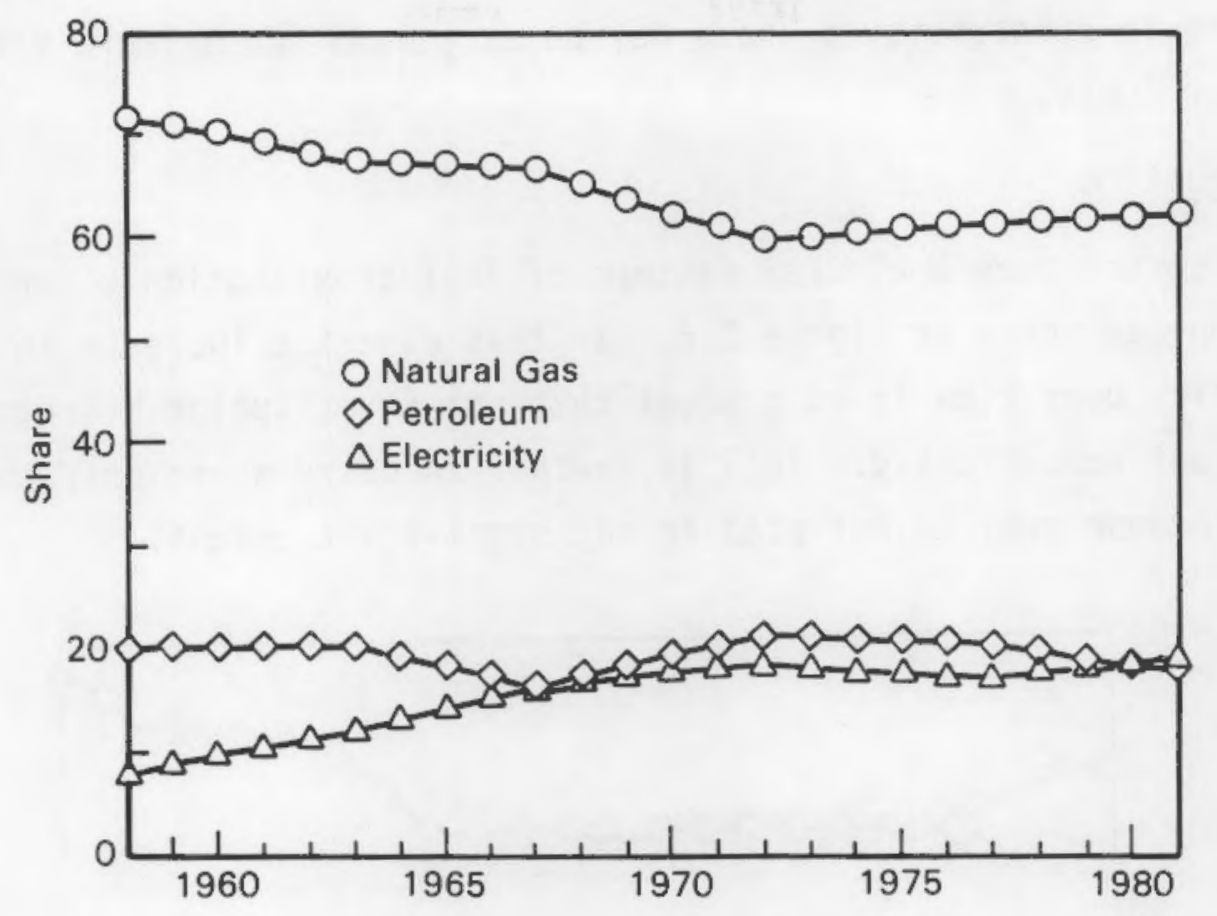

FIGURE 2.4 Petroleum and Natural Gas Mining - Fuel Shares

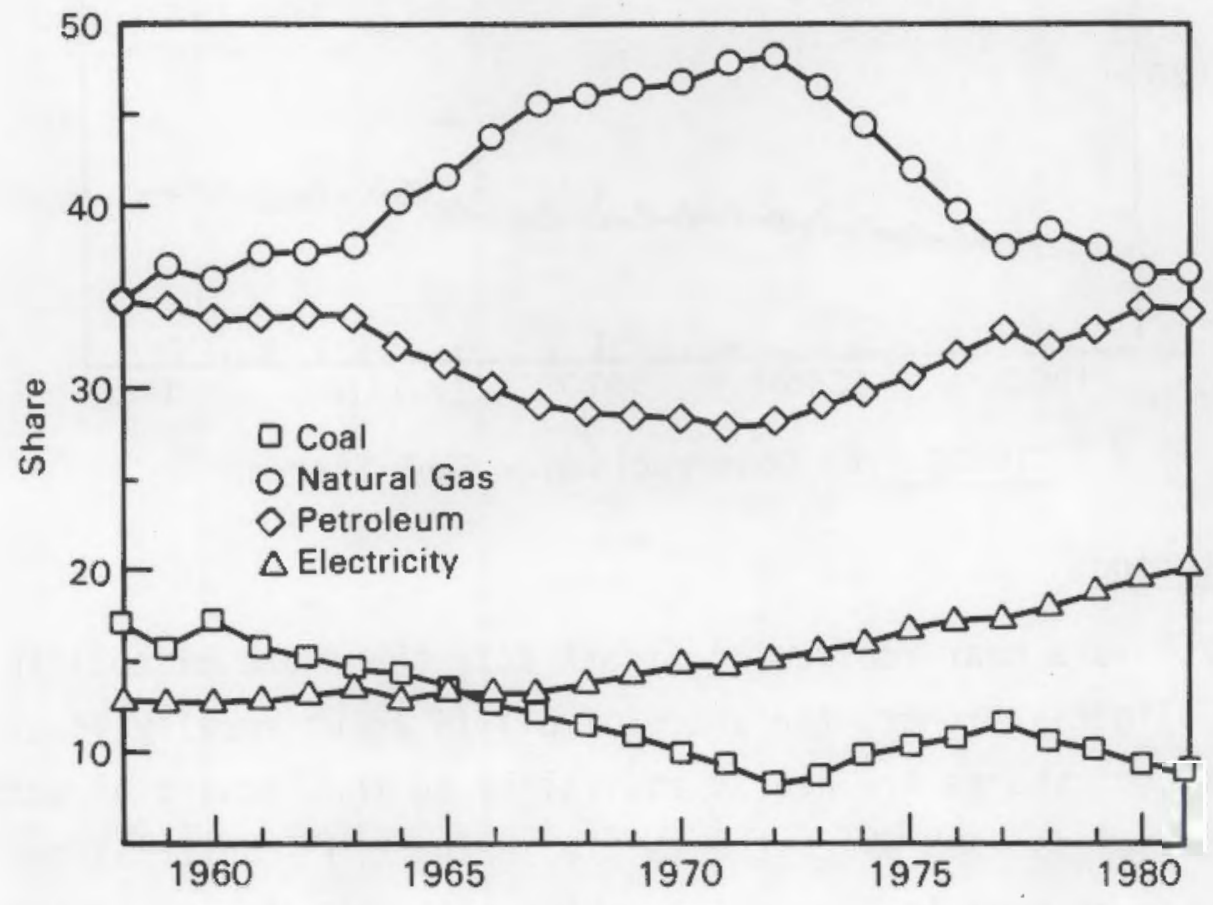

FIGURE 2.5 Other Mining - Fuel Shares 
appear to move in opposite direction at almost every period of time. Again the increase in electricity's share may be accounted for by more efficient use of other fuels.

\section{Construction}

In no sector does a clearer pattern of fuel substitution occur than in construction, as shown in Figure 2.6. In this case the increase in the share of electricity over time is so gradual that the substitution between oil and gas stands out dramatically. This is another industry where only three shares are shown because coal is not used to any significant extent.

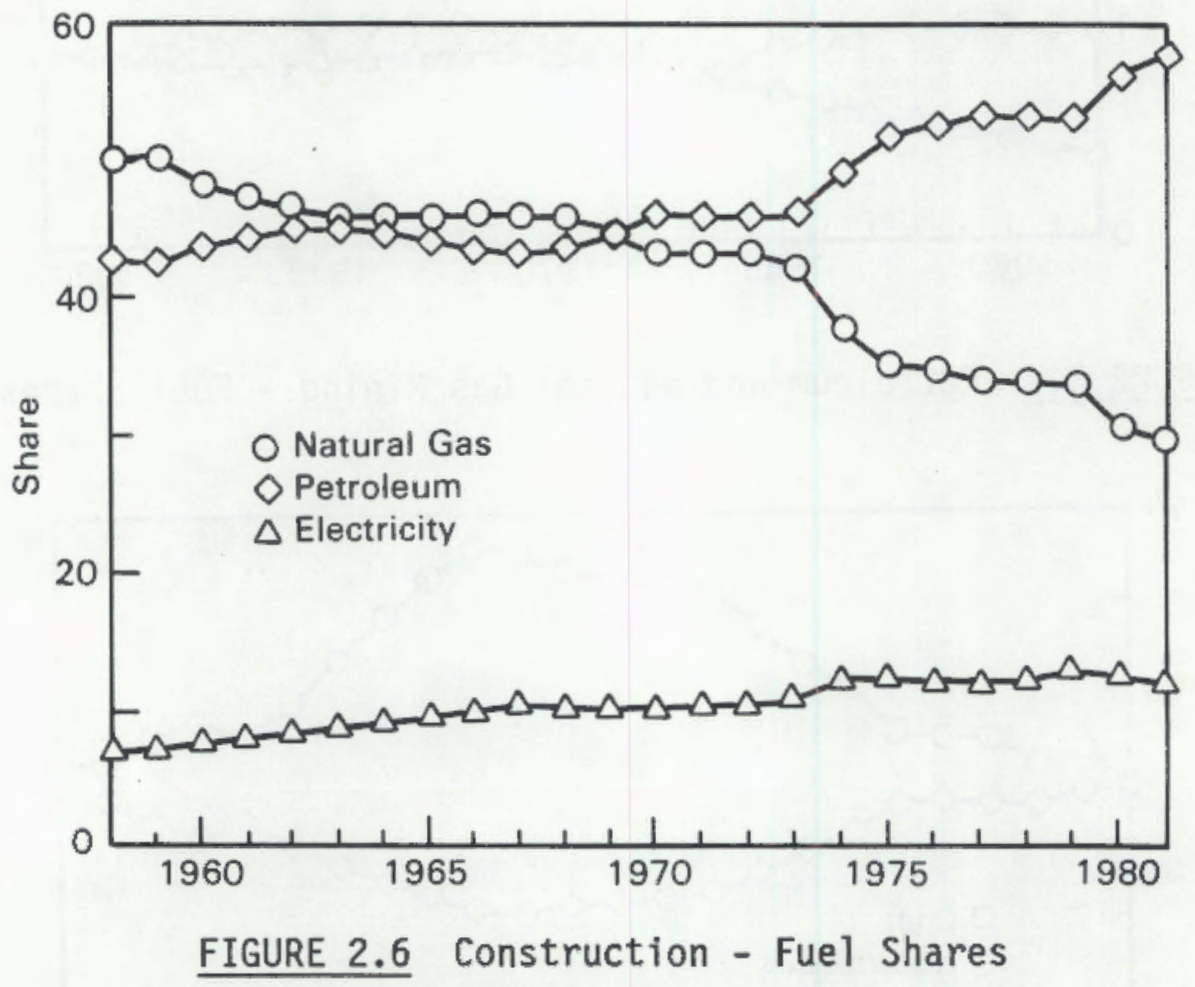

\section{Manufacturing}

Figure 2.7 is a near replica of Figure 2.3; the share of coal in manufacturing is slightly higher, the share of oil is about equally lower, but the other two fuel shares are nearly equivalent to the industrial sector as a whole. The closeness with which the manufacturing and industrial sector fuel shares track can be seen in Figure 2.8, which plots the four fuel shares for each of three different years--1958, 1972, and 1981. That the fuel shares of these two sectors behave similarly is not surprising. Manufacturing, as a 




fraction of gross product originating in the industrial sector, has grown from about 64 percent in 1958 to slightly more than 75 percent in 1981. With the exception of a slight decline in 1970 and 1971, manufacturing's fraction of industrial output has increased steadily over the entire period.

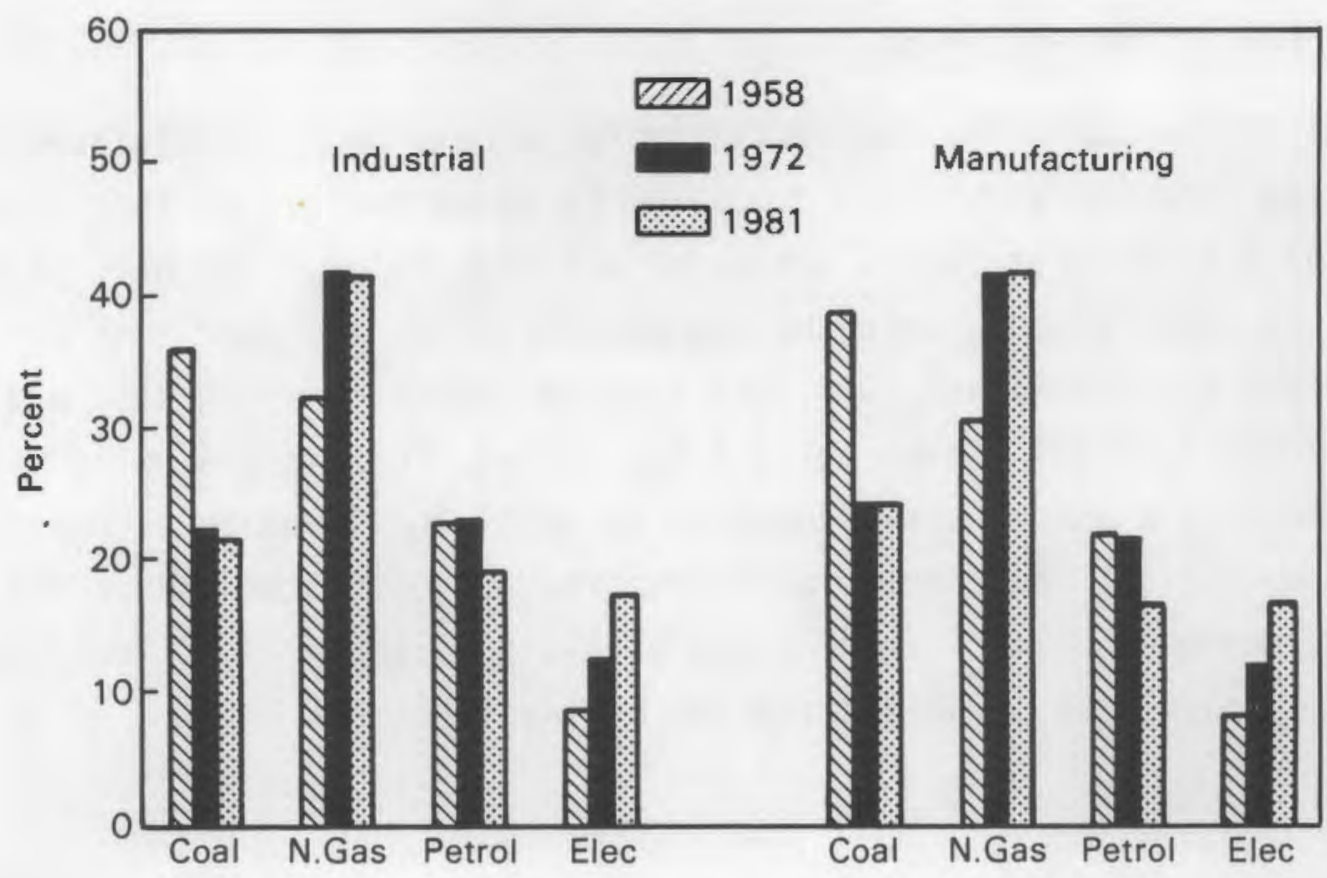

FIGURE 2.8 Fuel Shares for the Industrial Sector and for Manufacturing 
Although manufacturing is similar to the industrial sector as a whole, it is comprised of a variety of different industries. These industries show as much diversity as the aggregates that comprise the industrial sector. Thus the next stage in the characterization of fuel shares within the industrial sector is to examine these separate manufacturing industries.

\subsection{MANUFACTURING SECTOR COMPONENTS}

The National Energy Accounts that provide the source data for energy use in disaggregated industry sectors partition manufacturing into 72 sectors. For the purpose of this study, these 72 sectors have been aggregated into 19 industries. Manufacturing is organized into 20 2-digit SIC industries, but the aggregation used here does not necessarily correspond to those 2-digit classifications. Rather the aggregations used here reflect better the similarities of industry energy use. Thus primary metals (SIC 33) is disaggregated into three industries--primary ferrous, primary aluminum, and other primary metals. Similarly, stone, clay and glass (SIC 32) is identified here as three separate industries. To limit the number to a reasonable set, many industries have been combined into a single sector; for example, machinery is comprised of all machinery sectors except transportation equipment. The aggregation scheme used here is shown in Table 2.2, on page 2.4 .

\subsubsection{Fuel Share Patterns}

In this section the 19 manufacturing industries (and the five nonmanufacturing industries) will be displayed by using bar graphs that show three years of a.particular fuel's share for all industries. The bars selected represent 1958, the beginning of the period; 1972, the year just prior to the first OPEC oil shock; and 1981, the terminal year for which data are available. A bar graph for coal shares for all industries, for example, will show how each industry's use of coal, compared to total requirements of purchased fuel, stacks up against its industrial neighbors. By comparing industries this way, differences will be evident and will signal the need to look more closely at those industries. The examination begins with coal. 


\section{Coal Shares}

Coal shares for 24 industries are shown for three years in Figure 2.9. The typical pattern of coal use for the three years shown--1958, 1972 and 1981--is a continuous decline, with the largest decline occurring between 1958 and 1972. Eleven of the 19 manufacturing industries show this decline, while another six industries indicate a slight increase in coal use from 1972 to 1981 . One of the 20 industries, cement, shows a markedly different pattern. In this industry, the share declines about 10 percent from 1958 to 1972 , but then increases sharply to nearly 80 percent by 1981 . By 1981, only three industries--cement, primary iron and steel and pulp and paper--use as much as 20 percent of purchased fuels in the form of coal.

\section{Natural Gas}

The typical pattern shown by manufacturing industries for natural gas shares is one of a sharp increase in share from 1958 to 1972 with a somewhat smaller increase from 1972 to 1981 . This pattern holds for 14 of the 19 manufacturing industries shown in Figure 2.9. For cement, lumber and wood products, petroleum refining, and machinery, the share of natural gas increased from 1958 to 1972, but then declined between 1972 and 1981; but only in the case of cement was this decline more than 10 percent. Primary aluminum is the only industry in which the share of natural gas declines in both periods, 1958-1972 and 1972-198:. The decline in this latter period was about 18 percent, making aluminum's decline second only to cement, which declined nearly 30 percent.

\section{Petroleum Products}

There are two patterns for the change in petroleum's share over the time periods covered in Figure 2.10. Nine of the 19 industries exhibit a steadily declining share of petroleum; another nine first show an increase in the petroleum share, followed by a decline over the period 1972-1981. The single exception to these patterns is petroleum refining, which exhibits a decline from 1958 to 1972, followed by an increase to 1981. Petroleum refining, not surprisingly, has the largest share of this fuel, followed by pulp and paper. No other manufacturing industry sector used as much as 20 percent of petroleum products by 1981 . 


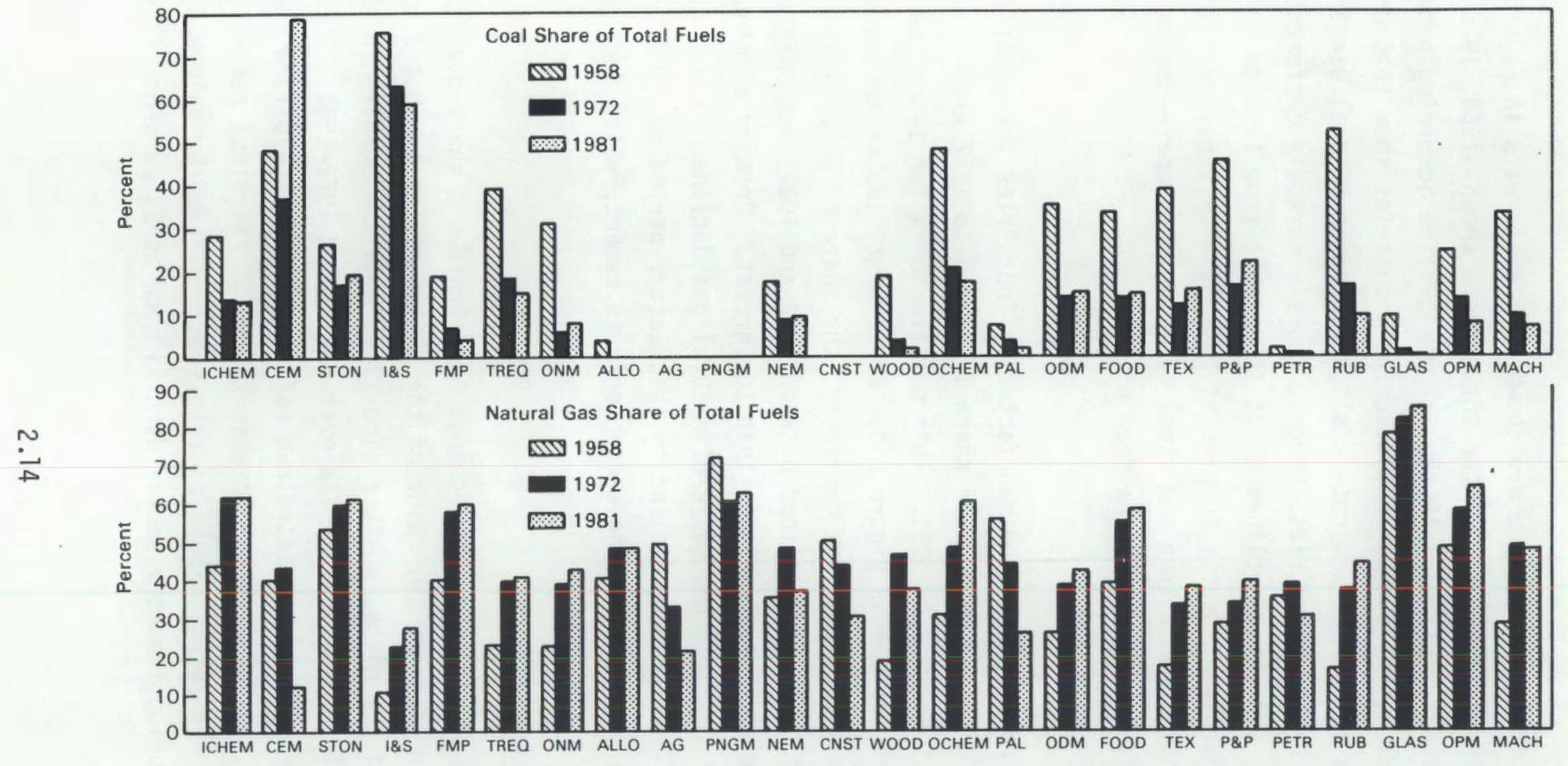

FIGURE 2.9 Coal and Natural Gas Shares, 1958, 1972, and 1981, All Industries 


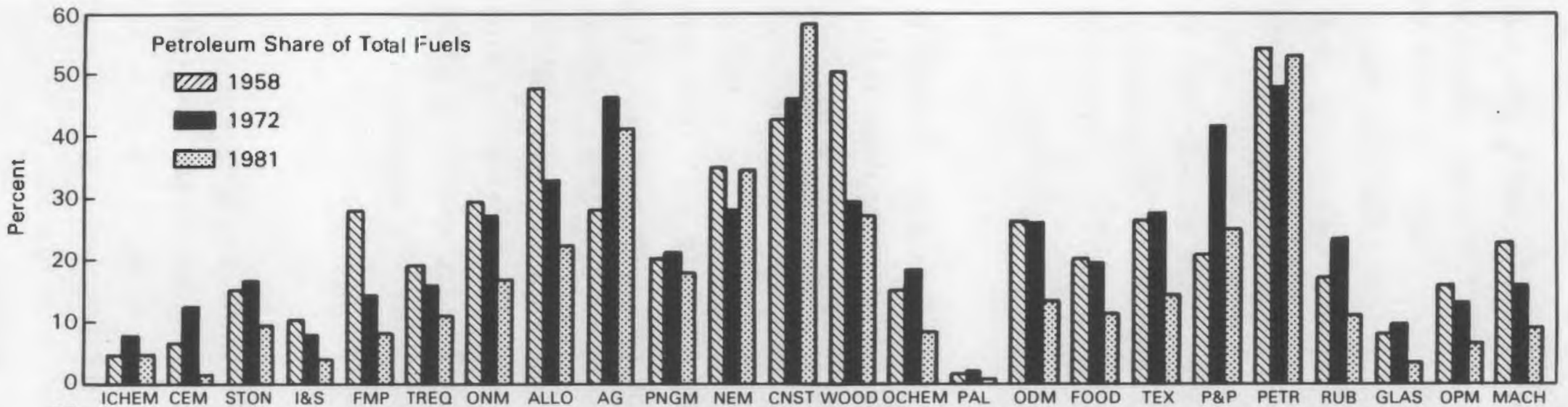

$\stackrel{N}{\sigma}$

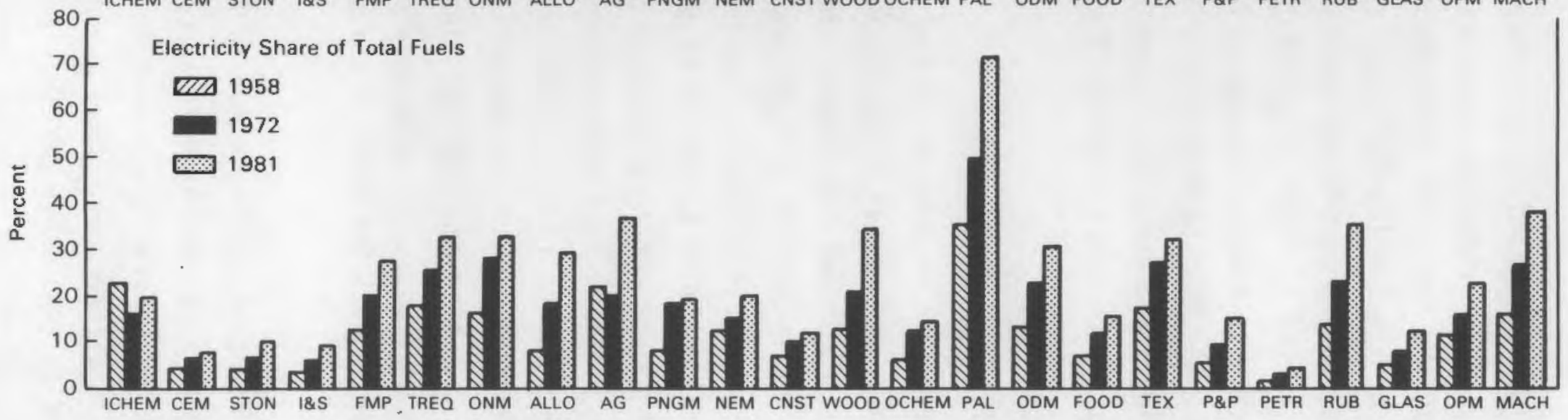

FIGURE 2.10 Petroleum and Electricity Shares, 1958, 1972, and 1981, All Industries 


\section{Electricity}

In all manufacturing, and in all other sectors as we11, the pattern is one of a steadily rising share of electricity, with only one exception: industrial organic and inorganic chemicals (Figure 2.12). In this industry alone, the share of electricity fell over the period 1958-1972 about six percentage points, but recovered two-thirds of that loss in the next period, to end with an electricity share of about 20 percent. This share would place industrial chemicals at 11 th of 19 industries. The industries with the largest shares are primary aluminum with an electricity share of over 70 percent, followed by machinery ( 38 percent), rubber and products ( 36 percent), lumber and wood products (34 percent), and textiles with an electricity share of about 33 percent.

\subsubsection{Exceptional Industries}

Four industries are exceptions to the typical pattern of industry energy use: cement (coal), primary aluminum (natural gas), petroleum refining (petroleum fue1), and industrial organic and inorganic chemicals (electricity). These industries are exceptions also because they are among the largest users of energy in the industrial sector. This section will examine these four industries in more detail to ascertain if they exhibit fuel share patterns that are contrary to the patterns followed by other industries. If there are exceptions to the patterns that most industries follow, these contrary movements may provide clues as to what forces are involved in fuel substitution. In addition to the four industries identified in the previous section, the textile industry will also be examined. Textiles are exemplary of industrial sector fuel share movements, and also show considerable change over time. The discussion begins with the textile industry.

\section{Textiles}

Fuel shares for textiles are shown in Figure 2.11; they are characteristic of the industrial sector insofar as coal use declines, electricity use increases and ofl and natural gas appear to move in opposite directions. But there are small differences. Coal use declines from about 39 percent in 1958 to 28 percent in 1967 , then declines even more rapidly to only 10 percent in 1974. The coal share then increases to 12 percent in 1977, drops one year, 


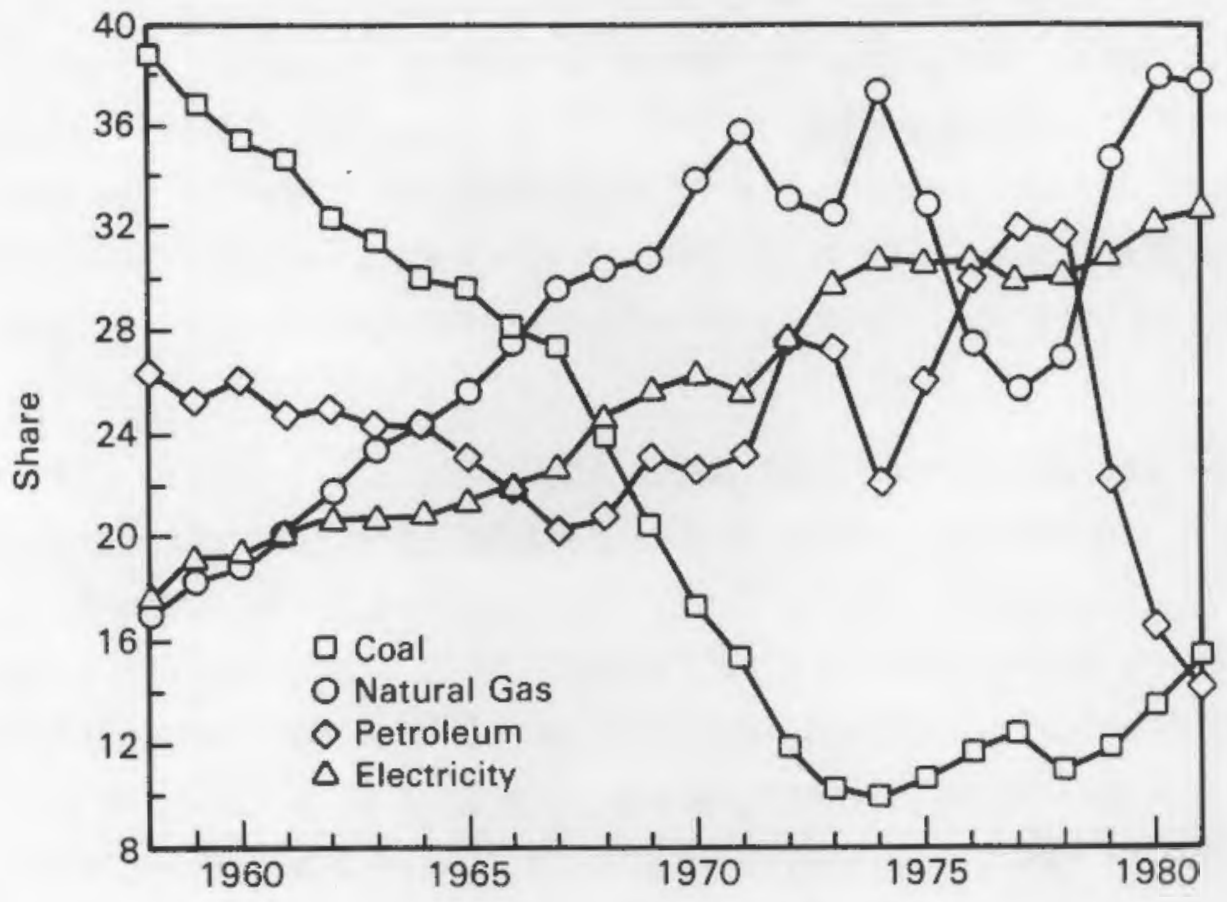

FIGURE 2.11 Textiles - Fuel Shares

but then increases to 15 percent by 1981. Compared to the industrial sector as a whole, the coal share in textiles undergoes a sharper decline and recovers somewhat more. The electricity share follows the industrial sector pattern by increasing over the period, but again shows more erratic movement than is typical. From 1973 to 1978 , for example, electricity's share remains nearly constant in textiles while increasing for the industrial sector as a whole. Textiles is typical also with regard to oil and natural gas share movements insofar as they appear to move in opposite directions, especially since the early 1970s. Although similar, the textiles industry again exaggerates the industrial sector shares for oil and gas--oil shares drop 8 percentage points for the industrial sector from 1978 to 1981, in textiles it drops 18 percentage points over the same time period. For all four shares, then, textiles is typical of the industrial sector, but share changes are more erratic than for the sector as a whole.

\section{Industrial Organic and Inorganic Chemicals}

This industry sector is comprised of two 3-digit industries that produce most of the bulk chemicals used in other industry processes. Nine of the top 10 bulk chemicals are produced in this combined industry. The formation of 
these chemicals usually requires a reaction promoted by extremes of temperature or by electrolysis. Accordingly, the most energy-intensive processes in chemical manufacturing are electrolysis, heat reactions, distillation, refrigeration, and evaporation. Most of industrial organics use fossil fuel as the major feedstock. The major inorganic chemicals fall under the heading of caustics and chlorine, industrial gases or inorganic acids (e.g., sulphuric acid).

The fuel share behavior that makes this chemical industry different from the industrial sector as a whole is the decline in electricity share from 1958 to 1970, as shown in Figure 2.12. Two factors could account for this relative decline in the use of electricity: 1) a change in the composition of the major chemicals produced--a shift out of chemicals produced by electrolysis, for example, less caustics and chlorine; 2) a relative increase in the production of energy-intensive chemicals that did not rely on electricity for production--most organics fall in this category. of these two, the latter is the more likely explanation.

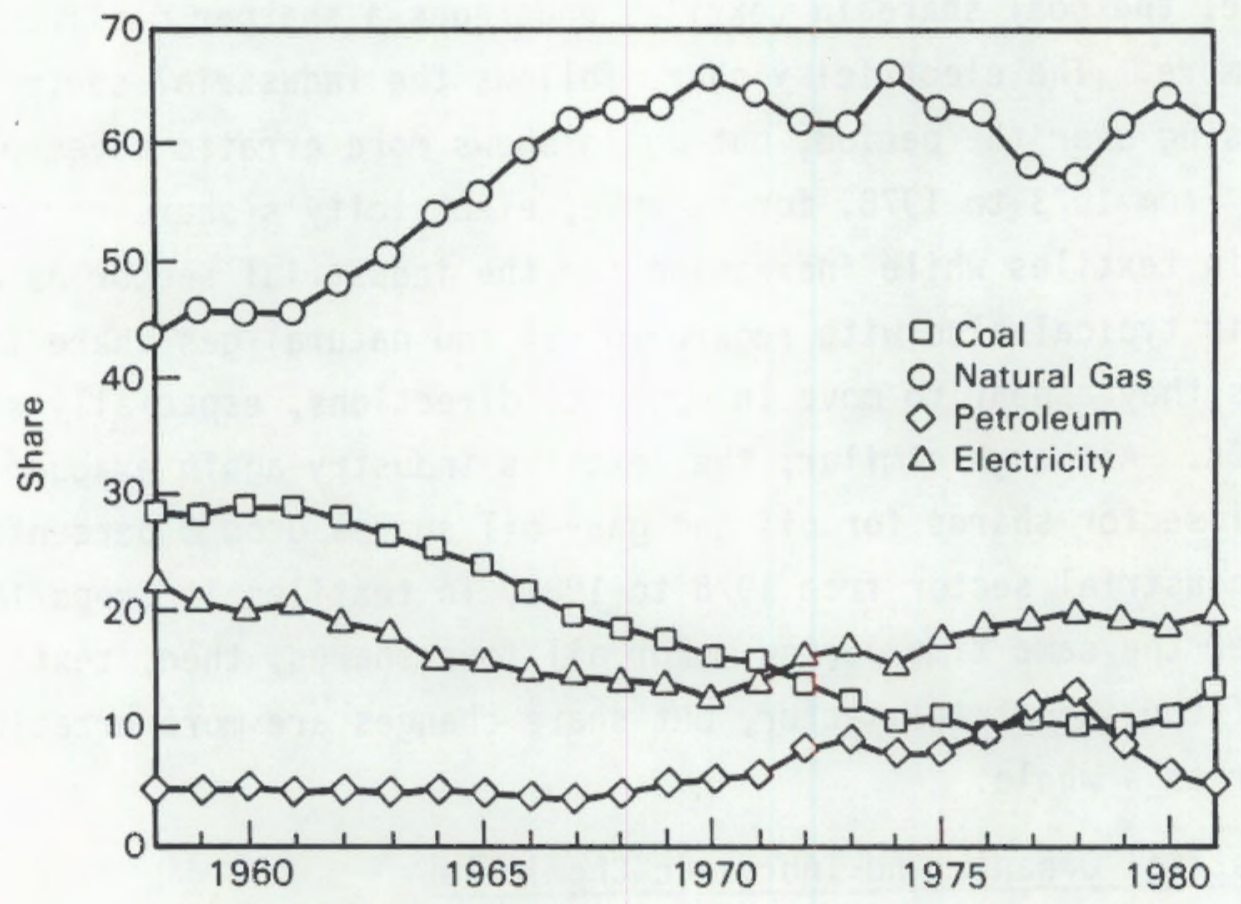

FIGURE 2.12 Industrial Organic and Inorganic Chemicals - Fuel Shares 
In absolute terms and relative to the rest of the industrial sector, chemicals have grown rapidly over this time period: in 1958 they were about 3.5 percent of industrial sector value added, in 1981 they had increased to 6.2 percent. Although the use of all chemicals has grown, organic chemicals have grown more rapidly over this period than others. And these are chemicals that rely primarily on distillation and heat treatment for production. This growth probably explains the decline in the share of electricity. Electricity use likely did not decline, it simply grew at a slower rate than the use of other purchased fuels, with a corresponding decline in share. This pattern of growth changed in the early 1970s as the relative price of fossil-based chemicals increased with rising fossil fuel prices. Concommitantly, electricity's share again began to rise.

On closer examination, then, the chemicals industry is not so different from the remainder of the industrial sector in its fuel share patterns. Although electricity's share declines until 1970, this fact is readily explainable as compositional shifts occurred in chemical output. And the pattern of the other fuel shares is a very famlliar one: coal's share first declines, then stabilizes; from the early 1970s until 1981, oil and natural gas show diametrically opposite movements. Although there are differences in levels, these patterns are much the same as for the industrial sector as a whole.

\section{Petroleum Refining}

Over the period 1958 to 1981 , the petroleum refining industry underwent some major changes that are reflected in changing fuel shares shown in Figure 2.13. On the raw material side, heavier and dirtier crudes have replaced the lighter and sweeter crudes that dominated the market in earlier periods. As a result of this supply change, the processing requirements have increased, forcing major new investments and raising the energy intensity of the production process. On the output side, there are several major changes that have had a profound effect on the structure of the industry: 1) automobiles have become more fuel efficient, so that gasoline, as a fraction of the final product slate, has declined; 2) the use of residual oil as a fuel has declined; and 3) unleaded fuel has come to dominate the gasoline market. The third of these product slate changes has again added to the costs and energy intensity of 
processing the crude, since higher distillate, oil-based additives have been substituted for lead. One would expect that the shift to middle distillates out of gasoline would serve to offset this shift somewhat, but this has not been the case. Desulphurization, required for the dirtier crudes, must be undertaken if the middle distillates are to be attractive as alternative fuels to coal or natural gas. At the same time that these changes have occurred, the petroleum refining industry has learned to economize on fuel use, especially natural gas.

The declining share of natural gas in petroleum refining is one of the things that makes this industry different from the industrial sector as a whole. The coal share, as large as electricity at the beginning of the period, has declined to virtually zero by the end of the period shown in Figure 2.13. That coal is used at all can be explained by the fact that, in addition to the refining industries, this sector includes two 3-digit industries that have low-grade heat requirements. Electricity's rising fuel share reflects the fact that the refining complexity has changed over time, requiring more motive power supplied by electricity. The decline in natural gas share has been stimulated by its unavailability (after the embargo) and by a readily available alternative--petroleum derivative fuels. But the movements of the natural gas and oil shares again are typical of other industries--when one declines,

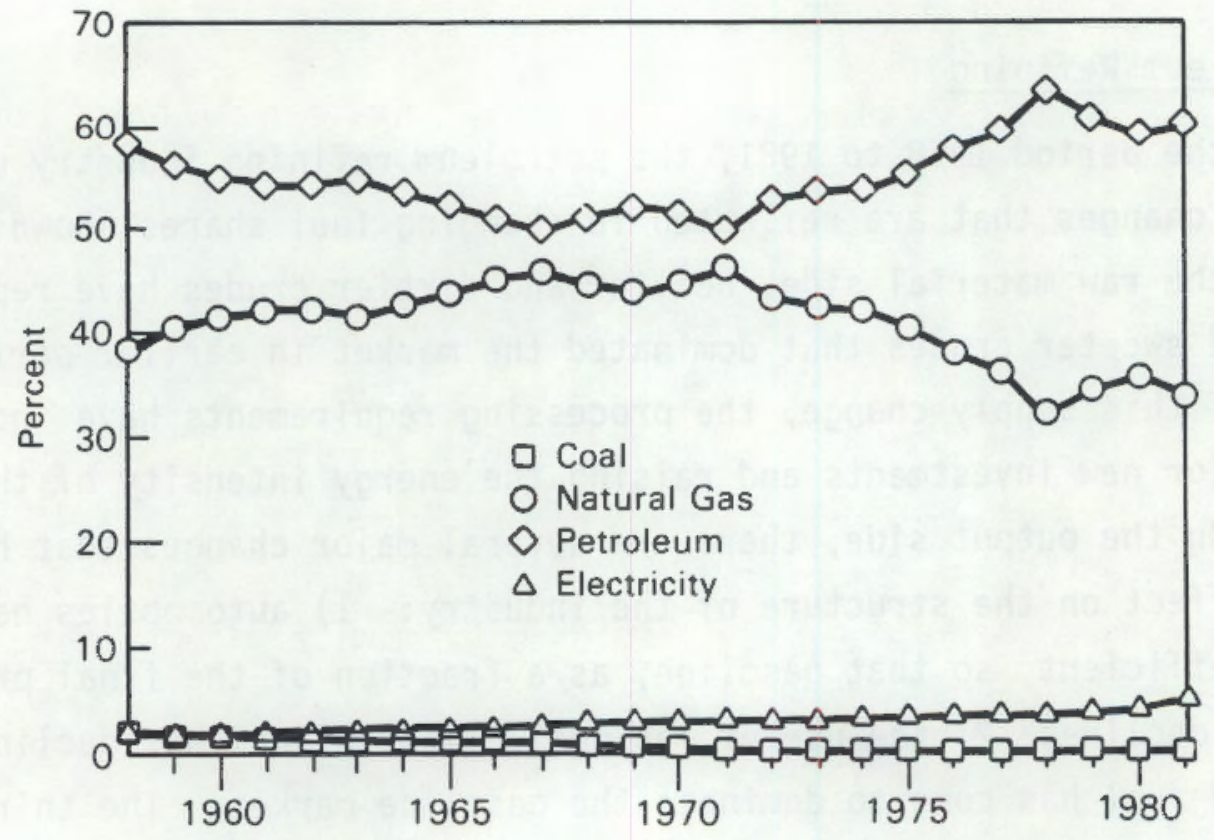

FIGURE 2.13 Petroleum Refining - Fuel Shares 
the other increases. There seems little doubt, from looking at Figure 2.13, that in this industry, 011 and gas are substituting for each other. Again the presumption that petroleum refining is uncharacteristic of the industrial sector is rejected.

\section{Hydraulic Cement}

Cement production in the United States has one of the highest ratios of energy costs to material costs of any manufacturing process. Cement is produced using either a wet or a dry process. Preheating and precalcining significantly reduce the energy requirements for the dry process. At the beginning of the period shown in Figure 2.14, most of the cement produced in this country used the wet process, and was fired in small, less energy-efficient kilns by small widely dispersed firms. By the end of the period, the number of producers had declined by more than half, most of cement was produced by the dry process using large-scale kilns, and a significant fraction of the industry had installed preheaters or other energy-conserving capital equipment.



FIGURE 2.14 Hydrautic Cement - Fuel Shares 
Most of these improvements occurred in the last ten years and explain the significant movement in fuel shares beginning in 1974. These energy-efficiency improvements reduced industry fuel requirements by 40 percent over the last ten years, with a 20 percent decrease per unit output. Most of this energy savings was at the expense of oil and natural gas, with coal effectively displacing most other fuels. Figure 2.16 shows the natural gas share declining after 1974, and the oil share almost disappearing by 1981. At the. same time, the coal share rises from below 40 percent in 1974 to nearly 80 percent in 1981. The only fuel share in cement that looks familiar is the electricity share. This has increased over time because the dry process, although it saves energy in the kiln, requires more energy for grinding the raw materials then does the wet process. Hydraulic cement, then, is clearly an exception to the general pattern of fuel share movements that are characteristic of the industrial sector as a whole.

\section{Primary Aluminum}

The aluminum industry, like the cement industry, has had strong economic incentive to improve its energy efficiency, since electricity prices have increased with oil prices and electricity is the major cost in the production of aluminum. The two major processes included in primary aluminum are the reduction of the metal from aluminum oxide (alumina), and the conversion of bauxite to alumina (the National Energy Accounts organize this chemical process as part of primary aluminum). Figure 2.15 shows the response of these fuel shares to these changing incentives.

Although the pattern of fuel shares in primary aluminum clearly suggests a substitution of electricity for natural gas over time, technologically, this substitution is impossible. There are only two major, commercial technologies for reducing alumina to aluminum--the Hall and Alcoa processes--and both of these are electrolytic. Why then the apparent substitution? The answer lies in the response of the aluminum companies to increases in fossil fuel prices.

Bauxite, the major source of alumina, is found primarily outside the United States; Australia, Surinam and Jamaica are major suppliers in the Western hemisphere. The process of converting bauxite to alumina is energy intensive, requiring kilning as a final oxidation step. About 2 tons of bauxite are 
needed to produce a ton of alumina. The response of the major aluminum companies to higher fossil fuel prices was to convert the bauxite to alumina before sending the raw material to the electrolytic reduction plants, both reducing total transportation costs and changing the energy content of imports. Before 1972, the major substitution that occurs within primary aluminum is between coal and natural gas; thereafter, the major substitution is between domestic and imported energy. The rising electricity share after 1971 thus reflects the decline in alumina reduction, rather than a substitution of electricity for natural gas. As is the case with cement, aluminum is clearly at odds with the typical pattern of fuel shares displayed by the industrial sector and most of the industries within it.



\subsection{GENERAL CHARACTERIZATION OF TRENDS}

For the private business sector of the economy, for the industrial sector, for manufacturing, and for many specific industries, there appears to be a common pattern of fuel share movement over the period 1958 to 1981 . This pattern is characterized by: 1) a gradual and steady increase in electricity's share; 2) a decline, accelerated during the late 1960s, in coal's share until the early 1970s when the share stabilizes; and 3) generally inverse 
movements in oil and natural gas shares, which are nearly diametrical after 1973. This pattern is pervasive, but not universal. Some industries, construction for example, do not use some fuels; other industries follow different patterns.

Among the industries that had noticably different patterns, a closer examination reveals that only two--cement and primary aluminum--are fundamentally different from the characteristic fuel share movements described above. In these cases, particular circumstances explain the fuel share movements within the industry. But the fact that there are differences is troubling. If there are fundamental differences in fuel share patterns among industries, could it be that the characteristic pattern is simply an artifact, arising despite the uniqueness of each of the industries? Or is this characteristic pattern an expression of the same set of pervasive forces acting on all industries, but being translated into different patterns in a few special cases?

In the former case, it is likely that trying to forecast fuel shares for the industrial sector will fail. In the latter case, there is a likelihood that fuel shares can be explained by examining the pervasive factors such as technological, economical and institutional forces. Accordingly the next step is to examine those forces that might explain fuel shares. 


\subsection{FACTORS INFLUENCING INOUSTRIAL FUEL SUBSTITUTION}

Understanding fuel substitution at the aggregate level, as measured by fuel shares, is different from understanding fuel substitution at the level of business decision making. In the aggregate, fuel shares are influenced by events that arise as a result of a myriad of decisions made by foreign and domestic consumers and governments, and of the interaction of all businesses. Although not identifiable with any particular industry, these forces affect each firm's decision making, and these decisions then affect fuel use. Before considering the microview of the specific firm within an industry, it seems worthwhile to show how this aggregate of behaviors coalesces into changes that can lead to a shift in aggregate fuel shares distinct from the changes that occur within individual firms. This simple explanation ignores institutional and other restrictions that may inhibit adjustments and assumes that market mechanisms are reasonably effective.

A major disruptive occurrence, such as a doubling of the OPEC oil price, will set into motion a chain of events that will alter the structure of the economy and subsequently alter fuel share distributions. To begin with, domestic oil prices will rise, but will not double, since non-OPEC sources will provide a modest buffer. The increased price of refined oil will be passed along to both ultimate consumers and businesses that use refined petroleum products as intermediate materials. Businesses wili substitute other fuels --coal or natural gas--for oil, thus bidding up the price of these other fuels. The price of electricity will also increase, since coal is the primary fuel used to produce electricity. All fuels and electricity, now somewhat higher priced, will add to the cost of the commodities produced, with energy-intensive commodities rising more than those commodities that used only small fractions of energy materials. When these cost changes have been passed along in full, consumers--individuals, governments, and foreigners--will find less energyintensive goods now with lower prices relative to goods with a higher energy content, and will substitute for the relatively cheaper commodities, both fuel and nonfuel. Imported goods that, for one reason or another, do not fully reflect these higher domestic energy prices will likewise be relatively less expensive and thus more attractive. 
The change in the composition of goods consumers purchase from domestic and foreign industry will feed back to the industries producing those goods. The result will be a shift in the volume and relative position of industries-energy-intensive industries will be relatively smaller, less energy-intensive industries will now be larger. Since the less energy-intensive industries have had the least incentive to substitute fuels, their fuel share distribution will change the least. However, these industries as a fraction of total output will now be relatively larger. But the less energy-intensive industries may well have had a significantly different composition of fuel use prior to the disruption, and these differences will now be given more weight. In short, both the compositional change among industries and the behavioral mechanisms operational at the firm level will have the effect of changing fuel shares. Since it represents a change in demand for the industry's products, the shift in composition that arises from such a disruption is one of the many factors that directly affect the business decision to substitute one fuel for another.

The objective of this section is to identify, discuss, and illustrate by examples the factors that influence this decision to switch fuel. The factors are classified under three general headings: technological, legal and institutional, and economic. After these major factors have been discussed, a number of industry changes are described and technological innovations highlighted that provide examples of these factors working to influence fuel substitution.

\subsection{GENERAL CONSIDERATIONS}

The perspective of the business decision maker is very different from the macro-perspective that views the economy as a whole. The equipment installed in a plant represents a major investment and is comprised of machines of different ages and efficiencies. The day-to-day decisions do not revolve around the purchase or construction of a plant; they focus on purchasing of materials, what and how much to produce, personnel requirements and commitments, and the incremental changes that will make the plant more efficient. Major equipment changes involve corporate financiers or outside financial arrangements and are not treated lightly. Housekeeping, retrofitting 
(that does not involve major changes), and routine purchasing decisions are all made on a day-to-day basis.

But the choice of fuels is not independent of the equipment. Some boilers will only burn one fuel; converting a boiler to dual-firing requires some retrofitting costs; and much equipment has to be replaced before alternative fuels can be used. Switching from one fuel to another, or developing the capability to readily change fuels may involve major restructuring of the plant. In many cases, fuel switching over time means that old plants are moved out of operation to be replaced by new, more efficient establishments. clearly the capital equipment decision is not independent of the fuel use within an industry.

Many factors, then, can influence the decision about both the equipment that uses fuel and the choice of the fuel itself. These factors are discussed below.

\subsubsection{Technological Factors}

Among the technological factors, three items stand out as important for fuel use: the existing stock of technology, research and development, and options for improving fuel use.

\section{Technological Stock}

Two characteristics of the stock are important: the equipment in place and the knowledge about efficient use. A snapshot of an industry at any given point in time will show a fixed amount of equipment in operation, maybe some that is idle, some possibly under construction, and more on order books or being fabricated. The technological stock or capacity is comprised of equipment available to be used and the equipment that will, in the relevant period of time, be available for use. Part of this stock is more efficient than other parts; this represents the more advanced commercialized applications of knowledge, but this is only part of what is known about efficiency. There is also knowledge in the form of processes that have been proved to work, but have not yet been commercialized, and there is knowledge that is still being developed. Finally, there is knowledge at a theoretical level that sets limits to how efficient the process may eventually become. Both the equipment in 
place and under development, and the knowledge that may be translated eventually into new equipment is part of the technological stock.

\section{Research and Development}

Most industries spend part of their revenues on research and development (R\&D) of new products or processes. As technology advances in research and development, the information passes from a conceptual idea, to the drawing board, to a prototype, to a pilot, then to a full-sized production facility. Engineers classify improvements as conventional, state of the art, developing, or conceptual. A conceptual technology is one that has been articulated, but not actively translated into a workable process. A developing technology is one under active investigation. A state-of-the-art technology is one that has been demonstrated, but is not widely used. And a conventional technology is one that has been fully commercialized.

\section{Energy Improvement Options}

Part of improving the efficiency of a plant is the selective application of some of the known stock of technology. These applications can be classed under two major headings: housekeeping and retrofitting.

Housekeeping. The items include a variety of mundane chores that fall generally under the heading of operation and maintenance. They may have, in total, a significant impact on energy use, but usually in very small ways. Among these are weatherstripping, replacing pipe insulation, turning out lights when not in use, or organizing efficient production schedules.

Retrofitting. This class of activities is the application of incremental changes that improve the efficiency of a given piece of equipment or process. Typical examples are computer controls for process or production systems, combustion control systems for boilers, and waste heat recovery devices such as blow heat recuperators or vapor recompressors.

\subsubsection{Legal and Institutional Factors}

Two major items under this heading are government regulations and contractual arrangements. The first of these is especially important because much of the environmental legislation proposed or enacted mandated pollution 
abatement investment that would have detracted from other investments. There were also major tax revisions during the period from 1965-1980.

\section{Legal Factors}

Energy use and the choice of technology may be affected by government regulations, particularly those aimed at protecting the environment or worker health and safety. Rules aimed at protecting the environment may impose additional costs or may require the installation of specialized equipment, or both. The existing stock of equipment is not usually able to immediately meet newly imposed standards so there is a period of transition during which some firms adjust while others disappear.

Another set of legal factors that influence business decision making is tax law. The three most important aspects of this law, at the federal level, are the corporate income tax, the tax rules for depreciating new plant and equipment purchases, and other tax incentives designed to promote or discourage particular types of business activity. Examples of the latter are the investment tax credit and special energy tax credits. Taxes at the state and local level are also important because they influence the location of industry.

A third legal condition, price controls, can influence business decision making and, consequently, fuel choice. Although, historically, price controls have been implemented only during war, they were in effect to varying degrees from 1971 to 1974. Price controls influence fuel choice through their distortion of market signals. If price controls prevent prices from increasing when a good is in short supply, rationing will occur on some other basis. Alternatively, if market forces would lead to a decline in price that is not allowed to occur because of controls, then surpluses will result. The market distortions that result from price controls discourage efficient allocation decisions that price signals provide. During the early 1970s, well past the initial OPEC ojl embargo, price controls over domestic petroleum and natural gas prevented as rapid an adjustment as might have occurred in the absence of these controls (MacAvoy 1983). In some cases the effect of price controls was moderated by the unavailability of certain fuels. 


\section{Institutional Arrangements}

The legal responsibilities of contractual arrangements may impose restrictions on a plant manager that limit his flexibility in responding to changing market conditions. A wide variety of events that are significant during the time period under consideration in this report could be classified under this heading. One that comes immediately to mind is the flight of some basic industries from locations with a strong union tradition to areas where labor unions have made little penetration. Shoe and textile manufacturing shifting from the northeast to the south is an example of such institutional effects. Such movements will have some influence on the choice of fuels, since fuels are not equally available in all regions.

Indeed, some of these shifts may have been the result of regional availabilities of different fuels. Historically, natural gas pipelines have been more concentrated in the mid-South, as a result of large natural gas supplies in Texas and Louisiana. From the mid-South, gas pipelines went first to the Midwest, the At1antic and the North Central states. Even today, some states, such as Maine and Vermont, use virtually no natural gas because few pipelines supply these areas.

\subsubsection{Economic Factors}

The economic factors that are important in determining the use of fuels can be classified under three major headings--factors that apply directly to the fuel, factors that apply to the equipment that uses the fuel, and other factors.

\section{Fuel Factors}

The two major economic considerations that apply directly to the fuels are the price of the fuel relative to alternatives and the fraction of total costs that fuel costs represent. These factors are considered in turn.

Relative Fuel Prices. The relative price that is appropriate for analysis will depend on how the fuel is used in production. In some cases, a particular fuel price should be analyzed relative to another fuel price--in multifired boilers this would be the case. If other factors can be substituted for fuel, or if fuel use is closely linked to specific equipment that is essential to the process of production, then the price of fuel relative to these other 
factors is important. If fuel use is unaffected by, say, the current hourly wage of labor, then the fuel price relative to labor prices is not a relevant variable for analysis. If two fuels are nearly perfect substitutes, the relative price of the fuels is the major consideration; if two fuels are imperfect substitutes, then the relative price remains modestly important, but other factors must now be given prime consideration (e.g., fuel conversion costs). Generally, the greater the extent to which the two fuels are substitutes, the more important the relative price will be.

Fuel cost Share. The relationship of fuel costs to total costs is another important economic consideration. If fuel costs are 30 percent of total costs, as they are in the cement industry, even a small change in fuel prices may dramatically change the profit position of firms, and thus influence the economic conditions of the industry. Clearly a cement company has a powerful incentive to search for cost-reducing measures in the face of any changes in fuel prices. But for another industry, energy costs may be a small fraction of the total costs of production--in machinery, for example, energy costs are only about two percent of total costs. Here, even a large percentage increase in fuel prices would have little effect on total costs, so would provide only modest incentive to reduce fuel expenses. The greater this incentive to economize, the more intense will be the efforts that firms undertake to find alternatives to high fuel costs.

\section{Equipment Considerations}

Over short periods of time, the equipment available for use in production is fixed; new production lines take time to appear. Associated with that somewhat fixed stock of equipment is a characteristic energy use profile. In most cases, this use profile detemines energy consumption in the short run. But there are exceptions to this rule--multi-fired burners and electric-boosted furnaces are examples. Over longer periods of time, existing equipment can be modified to provide additional flexibility or to alter the energy-use profile of that equipment. And over even longer periods of time, entirely new technological processes, in the form of new equipment, can be integrated into the production process. These points suggest a number of topics.

Equipment Use. New equipment purchased may be energy-using or they may be energy-saving. The introduction of robotics into production assembly lines 
is an example of an energy-using capital investment, undertaken to economize on labor or other, non-energy, material costs. The equipment conversion from a wet process to a long dry process in cement making would be undertaken primarily to save on fuel use or to increase capacity. These new equipment purchases will be undertaken as old equipment wears out or becomes obsolete, and as new capacity is required. A major factor in this capital budgeting process will be the cost of the equipment.

Capital Costs. When identifying capital costs, some items are included in the decision process that are not obvious. In addition to the purchase price of the equipment, the capital budgeting decision will take into account the following items: installation costs, operating and maintenance costs, tax treatment of the equipment (tax 1 ife, depreciation rules, tax credits, marginal tax rates on income earned from the investment), borrowing costs, stockholders' expectations about returns on equity, and the economic life of the equipment. Purchases of new equipment are weighed against retrofitting of old equipment, with expectations about the effective lives of the existing equipment and future fuel costs playing a major role in the decision. One of the factors that conditions these expectations is what will happen to the industry, i.e., what are the relevant factors other than just those that focus on fuel choice and equipment choice.

\section{Other Factors}

The outlook for the industry can focus on growth prospects, in which case, product demand is a major consideration, or it can focus on the ability of the industry to adjust--an ability influenced by the industry's structure.

Product Demand. Fluctuations in product demand affect the use of energy within an industry in a number of different ways; one important way is the effect of changes in product demand on the stock of equipment of the industry. A rapidly growing industry provides a favorable climate for investment in new plant and equipment, which usually means new, more efficient capacity. An industry growth rate that is low or declining, on the other hand, provides a discouraging environment for investment. An industry that has periods of rapid growth mixed with periods of steep decline may improve the efficiency of its capital stock during booms and abandon obsolete equipment during declines, thus adjusting more rapidly than other industries. 
Over short periods of time, an increase in product demand will increase energy use as more goods are produced. But this increase in demand can either increase the efficiency of energy use or decrease $i t$, depending on the effect of capacity changes on energy use in the industry. If an industry is operating at low levels of capacity, its energy use per unit of output may be relatively high, since a fixed energy use is spread over a lower level of output. Alternatively, low capacity may be associated with high energy efficiency if the machines in use are the most efficient ones. (a) Energy efficiency may improve if the increase in product demand moves the output of the plants currently in operation to a more nearly optimum position. As industry capacity is strained, less efficient plants are brought into production, lowering average energy efficiency. Over longer periods of time, the capacity of the industry will adjust as variable factors adjust in the short run.

Industry Structure. The structure of the industry will have some bearing on the way the industry adjusts, especially in the short run, and will therefore influence energy-use patterns. In a highly concentrated industry, with little effective domestic or foreign price competition, higher energy prices will be passed on directly in higher prices, with most of the adjustments occurring in the form of reduced output as consumers curtail purchases. In a highly competitive industry, in contrast, the producer will be forced to make most of the adjustments, until the number of firms in the industry adjusts and prices increase to reflect higher costs. Competitive firms will have more incentive to economize on the more expensive input, since their market power does not allow them to pass these costs on immediately in the form of higher prices. This structural effect will be moderated, somewhat, by the fraction that energy costs are of total costs. If energy costs are a large fraction of total product cost, the full costs likely will be passed on to the consumer in stages. Thus one would expect energy efficiency to improve more quickly in highly competitive industries than in less competitive industries.

(a) If the industry has low "overhead" energy use, the second line of reasoning might apply; in assembly industries, the first line of reasoning is more likely to apply. Which one of these arguments prevails in the industrial sector is an empirical question that we have not resolved. 


\subsubsection{Summary}

of the myriad of influences that affect fuel substitution in the industrial sector, the technological, legal and institutional, and economic factors provide broad umbrellas under which the influences can be grouped. To assist in the process of identifying the influences that apply to specific industries, the discussion is summarize by highlighting the important factors.

The more important factors are the following:

- Stock of knowledge about energy use

- Equipment that is embodied with that knowledge

- Research and development that leads to new equipment and knowledge identified by stage of development: conventional, state of the art, developing or conceptual

- Application of the stock of knowledge through housekeeping and retrofitting

- Environmental regulations such as the Clean Air Act of 1970

- Tax laws: corporate tax rates, tax treatment of depreciation, special tax credits such as the investment tax credit, and state and local taxes

- Institutional considerations such as labar union contracts, etc.

- Price of fuels--relative to other fuels, relative to other material inputs and relative to other factors of production.

- Size of fuel costs as a fraction of total production costs

- Costs of new equipment purchase and equipment modification (retrofit)

- Product demand--both current and expected

- Industry structure--competitive forces are a factor.

\subsection{INDUSTRY EXAMPLES}

This section examines several industries, quite different in structure, to see how these economic, technological and other factors may have had an influence on changing fuel shares within the period 1958 to 1981. Two periods are of particular interest, from 1967 to 1972 when environmental concerns were beginning to influence investment decisions, and from 1973 to 1981, when world oil prices rose sharply. These periods, unfortunately, also include events that confound the analysis of fuel substitution in the industrial sector. Price controls were imposed in August 1971, and were not phased out entirely 
until the 1980s. These controls disrupted the market and altered the allocation of resources. In one form or another, these controls continued to be applied to oil and natural gas until the end of the period under consideration. As a result, sorting out the separate influences of legal or institutional forces from economic or technological forces is nearly impossible.

Among the industries examined here, cement, primary iron and steel, pulp and paper, and petroleum refining correspond exactly to the industry definitions given in Table 2.2, page 2.4. The discussion of the first two industries relies on several major source documents: Garrett-Price (1985) and Portland Cement Association (PCA 1975) for cement and U. S. Department of Commerce, Office of Business Analysis (OBA, 1985) and Energetics (1985) for iron and steel.

In an economic sense, these two industries are organized along very different lines. Cement is characterized as a highly competitive industry, with many small firms located throughout the U. S. Iron and steel is less competitive generally, with only modest competition among integrated producers. The major domestic competition to the integrated producers is from mini-mills. Imports and alternative structural materials have provided steel with considerable competition in recent years, despite steel import restrictions.

\subsubsection{Cement}

Since the early 1970s, the cement industry has undergone considerable change, with three noticeable effects. The first is the shift from the wet to the dry process in the manufacture of cement. The second is the shift in fuel type from primary reliance on natural gas to a near dominance of coal. The third is the consolidation of small operations into much larger units. The effects of these three changs in the industrial structure of the cement industry are the focus of the characterization of the industry. After a discussion of these changes, attention will be directed to how economic and other factors contributed to these changes.

The Character of the Cement Industry

The cement industry in 1983 comprised 153 plants operated in the United States by 52 companies. In 1972, there were 198 plants run by 75 companies with more than 445 kilns in operation. By 1983, the number of kilns had 
declined to 274. These plants operated in all but 10 states, primarily because of the low value to weight ratio of both the raw material and the finished products. In 1983, after considerable consolidation, the five largest companies produced only 35 percent of total production. Between 1971 and 1982, significant foreign investment occurred in the ownership of cement companies, moving from virtually no foreign ownership to approximately 25 percent ownership.

Energy costs accounted for about 53 percent of value added in 1981, and 57 percent of total material costs. In 1971, the comparable figures were 25 percent and 43 percent, respectively. As a fraction of the value of shipments, energy costs increased from 15.6 percent in 1971 to 27.8 percent in 1981 . In this ten-year time period, total energy use declined by 40 percent, output declined by 7 percent, and energy use per ton of output declined by 20 percent. At the same time that fuel efficiency increased, there was a dramatic shift in the types of fuel used in the industry. The increase in fuel efficiency can be traced to a shift in the type of process used in cement production; the shift in fuel type clearly results from changes in relative fuel prices.

Cement can be produced by two different processes. The wet process adds water to the mix of limestone and other ingredients to form a slurry containing about 65 percent solids. In the dry process, raw materials are dried and pulverized into a powder. The wet process reduces the power needed for grinding the raw materials, but the water must then be driven off in the kiln, adding to the heating requirements to produce $\mathrm{clinker.} \mathrm{The} \mathrm{kiln} \mathrm{produces} \mathrm{clinker} \mathrm{by}$ converting the calcium carbonate into dicalcium and tricalcium silicate. After the clinker is cooled, the silicates are interground with gypsum to produce cement. Given state-of-the-art technology and if the wet process is used, a ton of cement requires about $6.12 \mathrm{Btu}$; if the dry process is used, energy requirements are only 5.12 million Btu. By adding a preheater or precalciner to the dry process kiln, energy requirements can be further reduced by nearly a million Btu, so that the process requires 4.15 million Btu per ton of cement (Garrett-Price, 1985, p. 2.18).

Over the decade from 1972-1982, process shifts were dramatic. In 1972, 60 percent of the clinker kilned in the United States was produced with the wet process; by 1982, these numbers had reversed, with 60 percent of cement produced using the dry process (PCA, 1984). Although this process shift continued in 
1983 (62 percent used the dry process), increasing power costs may limit the further transition from the wet to the dry process. These shifts have occurred, in part, as new, more energy-efficient facilities replaced older equipment. The average capacity of a kiln in 1973 was 191 thousand tons per year; by 1983, kiln capacity had increased to 322 thousand tons. Of the 38 kilns put in service since 1976, all but two (accounting for only 1.7 percent of added capacity) were dry process kilns. The dry process additions averaged 720 thousand tons per year and these new kilns comprise more than 47 percent of total dry capacity, while the wet process kilns averaged 220 thousand tons per year and accounted for only 1.3 percent of total wet capacity (PCA, 1983).

Fuel substitution was as dramatic as the process changes that occurred in the industry over the period 1972-1982. In 1972, petroleum products accounted for 13.1 percent of fossil fuels used by the industry, natural gas 48.3 percent and coal (and coke) 38.6 percent. Electricity comprised 6.6 percent of the purchased fuel and power requirements on a Btu basis, with fossil fuels accounting for the other 93.4 percent. Each ton of cement produced required the equivalent of 6.75 million Btu of energy. A decade later the energy use profile of the industry has changed significantly--a ton of cement in 1982 was produced with slightly less than 5.4 million Btu, most of which was in the form of coal. Electricity is now 9.4 percent of total energy use, with the other 90.6 comprised of fossil fuel and waste fuel. Coal use has increased to 82.8 percent of this total ( 87.7 percent if petroleum coke is included), with natural gas declining to 10.3 percent and other petroleum products accounting for only 1.8 percent (PCA, 1984).

\section{Influential Factors}

The dramatic change that the cement industry sustained over the past 15 years can be attributed to a number of the factors itemized in Section 3.1.4 above. The discussion will follow the same order as was followed for the classification of the factors.

Technological Factors. The change in technology between 1973 and 1982 is shown in Figure 3.1, drawn from Garrett-Price (1985) and PCA (1975). The theoretical fuel requirement shown as the first bar in the figure is derived from the heat requirement to calcine the input mix and then convert the mix to clinker. The heat requirement applies only to the pyroprocessing of the 
cement, not the grinding. Note that the average use, including all plants, dropped by 1.3 million Btu per ton of clinker between 1973 and 1982, a decline of nearly 22 percent. This improvement in efficiency was the result of two major changes--the shift from the wet to the dry process and changes in the typical size of operation. The first was clearly a move to economize on higher fuel prices; the second was, most likely, the result of the penetration of a new process (precalciners) and a change in the combination of least cost fuel and capital taken together.

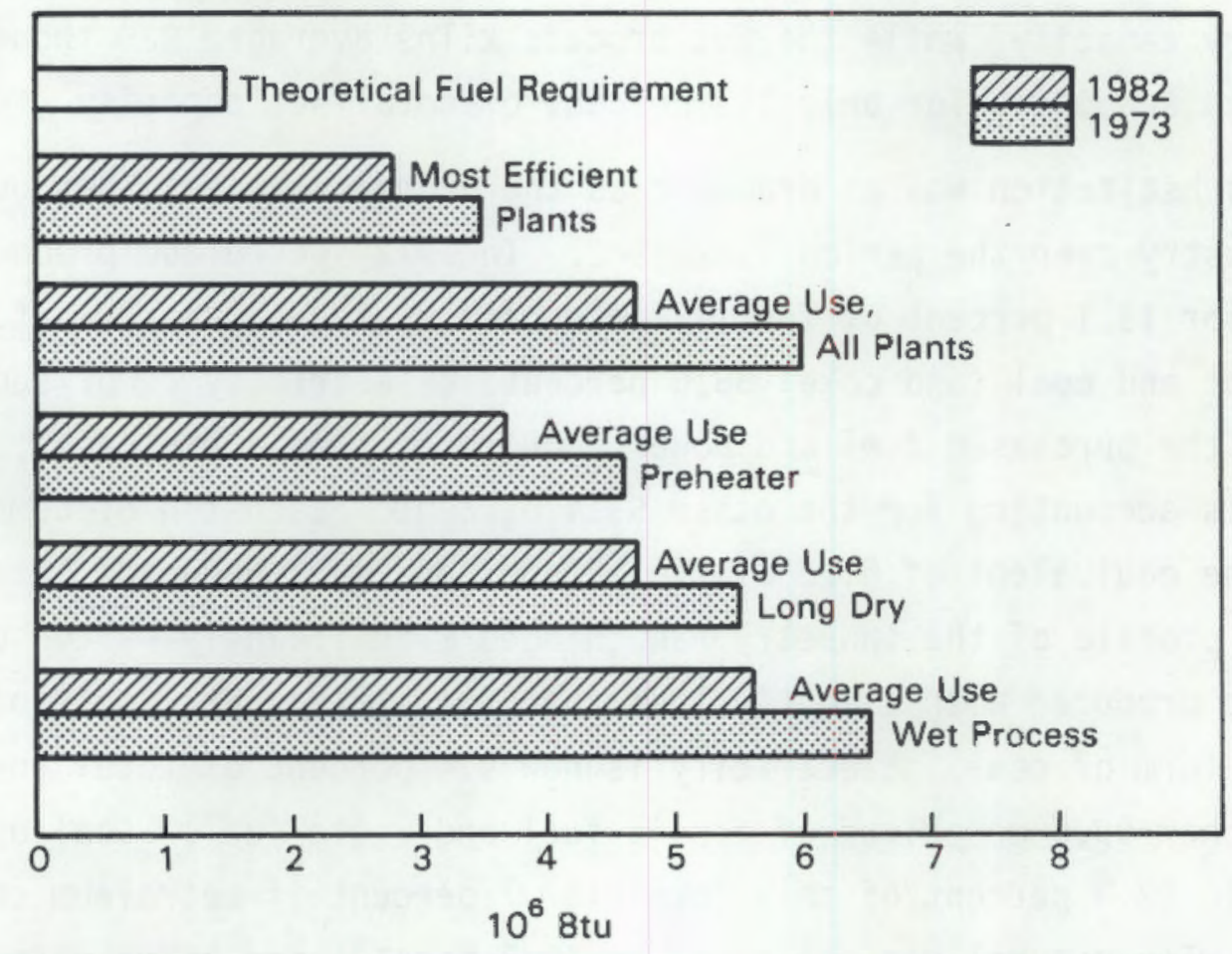

FIGURE 3.1 Efficiencies of Pyroprocessing of Cement at Different Plants 1973 and 1982 (10 ${ }^{6}$ Btu) (PCA 1975 and Garrett-Price 1985).

Institutional Factors. In cement, unlike most other industries, environmental legislation did not have the effect of reducing coal use, although it is possible that these regulations altered the scale of production. It is clear from the shift out of oil and natural gas into coal during a regime of higher energy prices that the cost savings of using coal outweighed the disadvantages of using coal. The major disadvantage of using coal is the need for bulk storage areas and coal-handling equipment; these requirements and the fact that coal is dirty have been collectively referred to as the "hassle factor." Another disadvantage of burning coal is that environmental regulations require that a bag house or other precipitator be installed to collect fugitive ash. 
(In the manufacture of cement this is less a problem than in other industries, since the fly ash can be incorporated into the product. Any fugitive dust from either the firing of the $k i l n$, regardless of fuel type, or coal grinding would have to be collected.) The necessary environmental controls were installed, as were the facilities to handle the bulk fuel. Either of these requirements could have promoted the increase in scale of operation. It is likely that both of these factors would have stimulated larger plants, allowing the larger capital cost to be borne by a higher level of output. But there is no definitive evidence, at this time, that would allow one to decide which of these two causes is the more important. Indeed, the efficiency of larger kilns may have been the deciding factor rather than environmental or facility requirements.

Another institutional factor that may have some effect on the extent of change in the cement industry is the purchase of facilities by foreign investors. Foreign ownership increased during this period, and the foreign companies that purchased cement facilities were cement producers abroad. Their knowledge of more advanced technologies in Europe and Japan may well have been transferred to their U. S. subsidiaries.

Economic Factors. The most significant factor responsible for the change in the cement industry was the energy price increases of 1973-1974 and 1979. Because energy is such an important cost component of cement, the energy price hikes caused cement producers to change their method of operations. Cement manufacture went from being a small-scale, local enterprise to a much larger scale operation with fewer domestic producers. In adapting to higher energy prices, cement manufacturers changed processes, changed fuels and changed the size of operation. As a result of these changes, cement uses 20 percent less energy than it did in 1972, on average. If all plants operated at the same enegy intensity, as the most efficient plants, current energy use could be reduced by another 50 percent. Clearly the changes have been dramatic, but much room for improvement remains.

\subsubsection{Primary Iron and Steel}

Apparent consumption of steel in the U. S. doubled from 1958 to a peak in 1973 of 123 million net tons, but has declined subsequentiy to about 95 million net tons in 1984. Since 1965, consumption of steel has not kept pace with 
the growth of GNP, declining from a rate of over 100 tons per million dollars of GNP to a 1982 low of 52 tons. At the same time that industries have continued to substitute other materials for steel, the growth of mini-mills and continued growth of imports have put constant market pressure on the large, integrated producers. This continuing duress has made it difficult for the integrated producers to undertake the investment needed to adopt the newer technologies that would allow the industry to remain competitive. Adding to the uncompetitive structure of the industry is the fact that domestic stee] workers earn higher wages, on average, than workers in any other sector of manufacturing, and far higher than foreign producers. These factors, along with higher energy costs, have brought about substantial changes in the primary iron and steel industry over the past two decades.

The Character of the Steel Industry

The primary iron and steel industry includes firms that are classified as blast furnaces and steel mills, firms that manufacture additive alloys and other electrometallurgical products, firms that produce steel wire and related products, firms that are engaged in the cold finishing of steel shapes, and firms that produce steel pipe and tubes. In 1972, the industry had 970 establishments and employed a total of a half-million workers (570 per establishment). Shipments were valued at $\$ 28.1$ billion, of which 43.1 percent was value added, the other 56.9 percent going to the purchase of materials. In 1982, the number of establishments had increased by 10 percent (to 1068) with an average employment of 342 wage earners per plant. This represents a 40 percent decline in the number of workers employed in each establishment over the decade. The products that were shipped from these establishments were valued at $\$ 46.7$ billion, of which 31.5 percent was value added. Thus factor payments--the returns to Tand, labor and capital--per dollar of sales declined by about 27 percent over the decade.

These changes are a continuation of trends that have dominated the primary iron and steel industry since the end of World War II. Although steel consumption grew modestly from 1945 to 1966, it has grown only slightiy since. One major trend, then, is the relative decline in the use of steel in the U.S. economy. This trend is common anong all major developed countries of the world. A second major trend is the increase in the use of imported steel: 
as a fraction of new supply, imports increased from about two percent in 1958 to 15 percent in 1981. Import pressures will continue as long as world capacity remains in excess of world denand. A third major trend has been the evolution of the industry as new technologies have been adopted. These technological changes have been evidenced both in changes in processes and changes in the organization of the industry. In 1960 three percent of industry output was produced by mini-milis--companies that use electric-arc furnaces and primarily scrap to produce a variety of iron and steel products. By 1980 mini-mill output had grown to 20 percent of total output, with the remaining 80 percent produced by the traditional integrated mills. As mini-mills grew in importance, there were also major changes in the technology of producing steel.

The basic process of producing steel in integrated mills is little changed from the process used at the turn of the century. Iron ore is mixed with limestone and introduced into a blast furnace fired by coke. As the charge moves down the vertical furnace, the oxidized iron in the ore is reduced, the oxygen combines with the carbon from coke to produce carbon monoxide (which is recycled as a fuel) and the limestone chemically reacts with a variety of impurities to yield molten iron metal and slag. The molten iron is tapped and transported to another furnace that further removes impurities to yield steel. Iron is converted to steel using either a basic oxygen furnace or the older, and soon to disappear, open hearth furnace. In 1958 about 91 percent of raw steel was produced by open hearth furnaces; by 1983, this process accounted for only seven percent of total steel production. The basic oxygen furnace (BOF) has largely supplanted the open hearth process because it is more efficient. Typically, a BOF can produce a 300-ton batch of steel in 45 minutes, whereas the open hearth process requires from one to seven hours. The open hearth furnaces that remain in operation are used primarily as backup to the BOF or when additional capacity is required.

Once the iron is converted to steel, two techniques can be used to convert the raw steel to products. In the older technique steel was poured into ingot molds. After the ingots cooled, they were transported to mills where they were broken down into blooms, billets or slabs. The more modern technique ladles the molten steel into a continuous caster that produces the blooms, billets or slabs directiy. The forming of ingots and conversion of these to 
semi-finished steel products requires that the steel first be cooled, then reheated before being broken down into semi-finished products, which makes the continuous casting process much more energy efficient.

An even more energy-efficient process bypasses the iron-making stage and makes steel directly from scrap. An electric-arc furnace (EF) in this operation plays the role of the BOF in integrated plants. This technology is used primarlily in the mini-mills, which have lower unit energy costs, have lower unit labor costs, and can be located near the source of the raw material--scrap. Because of these lower costs, the mini-mills are more competitive with imports than are the integrated producers. This distinct cost advantage has allowed the mini-mill sector of the industry to grow from 3 percent in 1960 to 24 percent in 1985. But there is a limit to the growth of this sector since the scrap has to come from somewhere. But these limits are not expected to be reached for another decade when mini-mills will have captured between 32 and 40 percent of domestic steel production (0BA, 1985).

other process improvements (in addition to the BOF, continuous casting and mini-mills) have occurred over the recent past or are likely to occur in the future. Beneficiation and pelletizing of ore have become standard practices as the quality of iron ore reserves has declined. Direct reduction of ore, a process that eliminates the need to convert coal to coke, is currently in the pilot stage in Germany, with production facilities being constructed in South Africa. This process, called the Kohle Reducktion (KR) process, was developed in West Germany and is currently under consideration as a demonstration project by both Weirton Steel and U. S. Steel. Direct reduction using the KR process is more economically attractive than processes that use natural gas (Basta 1986).

In melting scrap, two technological advances are currently under investigation that have the potential for significantly lowering costs. The first of these is a continuous arc furnace that would substitute for the batch EFs currently in operation. Called "Consteel," this process is said to reduce the cost of making a ton of steel from scrap by as much as 14 percent. The second process, called an energy optimizing furnace (EOF), does away with electricity as the heat source. Instead, natural gas is used a preheater 
until heat is generated chemically as carbon from both scrap and coal reacts with large amounts of injected oxygen.

Technological innovations are also on the horizon that will affect the way steel is handled after it leaves the furnace. Ladle metallurgy is the phrase used to describe the further treatment of steel after it leaves the furnace. Treatment of the steel within the ladle has two advantages--the furnace is not tied up and the metal can be more precisely tailored for specialty steels. Past the point of tafloring the metal, there are technological advances in the casting process that will also affect costs. Thin strip casting is one development that could eliminate the stage of production that currently yields semi-finished products. U. S. Steel and Bethlehem Steel are currently exploring this option. An even more advanced concept allows the production of strip by cooling the metal as it comes in contact with a rapidly spinning plate. An extension of this process rapidly cools steel to form "metglass," an amorphous material that has many of the properties of both metal and glass.

Technological innovation in steel processes has had much less effect on energy use in this industry than in the cement industry. As a fraction of total purchased inputs, energy use has declined only about seven percent over the period 1958 to 1980 . This modest decline is swamped by the year-to-year changes that occur as a result of business cycles. For example, in 1971, a year in which capacity utilization was below 70 percent, steel making required 110 thousand Btu per constant dollar of output. Three years later, when capacity utilization was at 100 percent, only 91 thousand Btus were required. This cyclical movement of nearly 17 percent is considerably more than the trend reductions in energy use. Since 1979, the industry has been in a prolonged period of recession, so recent comparisons do not indicate significant improvements. But from 1958 to 1978 there were significant shifts in energy use.

As the open hearth disappeared and sintering and beneficiation of ore became common practice, the fraction of coke and breeze to total fuels declined. In 1958, coke and breeze accounted for nearly 65 percent of total fuel use. By 1973, that fraction had declined to 55 percent. With basic oxygen and electric furnaces substituting for the open hearth process, electricity became 
more important as a fuel source, increasing from 10.4 to 18.1 percent over the same time period. With natural gas a major fuel source for sintering and beneficiation, its share also increased from 5.8 percent to nearly 12 percent in 1973. These trends have continued since 1973, despite the fact that fuel prices have increased dramatically. By 1980, electricity's share had increased to 22.4 percent, and natural gas use had increased from 11.8 percent in 1973 to 13.1 percent in 1980 , despite relatively higher gas prices and gas curtailments during the mid-1970s.

\section{Influential Factors}

More than 15 years after the first successful effort to protect the steel industry from international competition the future of big steel in the U. S. remains uncertain. Although substantial technological improvements have become common practice, domestic integrated producers remain less efficient than the most efficient foreign competitors. There are several reasons for this, which we examine in the same order as the topics presented in Section 3.1.4.

Technological Factors. Several proven technological developments have become available over the last 20 years in steel making that have increased the efficiency of steel production. The most significant of these are beneficiation and sintering of ores, the replacement of the open hearth furnace with either the electric-arc or basic oxygen furnace, continuous casting rather than ingot processing, and, more recently, the adoption of computer controls. These technologies have not penetrated the integrated sector of the U. S. industry to as great an extent as in other major steel-producing countries such as West Germany and Japan. Indeed, no new integrated facility has been constructed in this country since the 1950s, although some firms have retrofitted to take advantage of the latest technology. As a result, U. S. steel lags behind other major steel producing countries in both efficiency and technology. The reasons for this are both institutional and economic.

Institutional Factors. Import restrictions on foreign steel products were first imposed in 1969 based on the argument that the industry needed the protection in order to modernize its facilities. The first five years of protection saw big steel diversify into energy, appliances and other consumer products and actually reduce investment in new plant and equipment. This does not provide a very convincing argument that import restrictions aid 
modernization. Instead, it provides evidence that protection of domestic producers eliminates the international competition that encourages the efficient operation of domestic integrated producers.

Labor has also had an important effect on the competitive position of the domestic steel industry. Industry-wide bargaining and one of the strongest industrial labor unions have provided the steel industry labor force with one of the highest industrial wage rates in the world. In 1980, average annual hourly compensation for steel production workers was over $\$ 17$, while the comparable figure for all U. S. manufacturing was $\$ 9.28$ (OBA, 1985). If labor costs were comparable to those in other countries, domestic integrated producers could produce steel at costs below the production costs of other major steelproducing countries such as Japan and West Germany when transportation costs are included. The domestic labor costs of a metric ton of wire rod produced by an integrated mill is about $\$ 150$. This compares to about $\$ 90$ in Germany, $\$ 60$ in Japan, and about $\$ 60$ for domestic mini-mill producers. Since 1979 , the industry has attempted to bring these higher costs under control by monitoring costs more closely, terminating operations in the most inefficient plants and eliminating industry-wide bargaining.

Economic Factors. During the period 1958-1966, the productive efficiency of the integrated steel industry compared favorably with manufacturing as a whole. Total factor productivity grew at a rate of 1.8 percent per year, more than half a percent faster than manufacturing. Since then, however, steel has lagged behind other manufacturing and in fact its productivity has declined at an annual rate of 0.1 percent per year. The decline of steel has been the decline of its integrated segment. Major causes of this decline have been the changing composition of the $U$. S. economy toward services rather than goods; more frequent business cycles and higher inflation rates since the mid-1960s; the decline of the automoblle industry due to foreign competition; and loss of market share to domestic and foreign substitutes such as plastics and concrete, and to steel from domestic mini-mills and foreign producers (OBA, 1985).

This decline has occurred in part because returns to steel making have not been high enough to sustain the investment program that would modernize and upgrade existing facilities. Since 1966 the after-tax return on capital 
of the integrated steel companies has been less than half of the all-manufacturing average (OBA, 1985). To finance the modernization that has occurred, the steel companies have increasingly turned to debt finance, have become more leveraged, and subsequently have had their debt service costs increase as financial institutions assign them a higher risk profile. But restructuring is currently under way that may alter that picture in the future.

Domestic integrated producers have restructured their operations in a number of different ways. Some firms have sold off assets to raise the cash to finance new investment--Armco and LTV Corporation are examples. Some capacity has disappeared as less efficient plants have shut down. Still other companies have consolidated or formed joint ventures with foreign producers-Kaiser Steel now operates under Joint Japanese and Brazilian ownership and Inland Steel and Mitsui are investigating the possibility of a joint venture. This restructuring has led to more efficient operations for domestic producers.

Evidence of efficiency improvements has appeared since 1980, despite the continued slow growth of steel output. In 1985, 40 percent of steel production was using continuous casting compared to only 20 percent in 1980 . Labor productivity has increased 19 percent annually between 1982 and 1985, largely at the expense of employment. In consequence, labor costs have declined from a peak of $\$ 22.72$ per hour in 1982 to $\$ 20.24$ in 1984 . These improvements will have to continue for a sustained period of time if the integrated sector of the industry is to regain the competitive position it had in world steel production a quarter-century ago.

\subsubsection{Other Industries}

There are several other industries that have made dramatic changes in fuel use since 1972. Pulp and paper, chemicals and petroleum products are industries that have a large fraction of costs for fuels and feedstocks, and all of these industries have altered their fuel use patterns. Fuel use in each of these industries will be briefly examined to highlight the changes that have occurred since the early 1970 s.

\section{Pulp and Paper}

The pulp and paper industry produces pulp, paper and paperboard from wood fibers. The wood fiber is separated from the lignin either chemically 
(using the Kraft or neutral sulphite--NSSC--process) or mechanically (often combined with steam). The wood fiber is then bleached, washed, and slurried onto a screen to form paper or pulp. Pulp is usually cut and packed into bales, paper is rolled or converted to final products (different papers, envelopes, newsprint, containers or building materials).

Environmental legislation and higher fuel prices have both had a significant effect on the amount and types of fuel used in the pulp and paper industry. The clean air and water acts that became effective over the period 1965-1972 forced major modification of pulp and paper mills to bring them up to emission requirements. This stimulated the search for alternative ways of disposing of biomass and chemical wastes used in the Kraft and NSSC pulping processes. One efficient method of conversion was to burn the lignins, separated from the wood fibers, as a substitute for purchased, fossil fuels. This solved one of the problem of waste disposal. Higher fuel prices in the early 1970s further promoted efficient methods of energy use with the result that fuel use per unit of output decreased substantially. In 1972, the industry used 32.6 million Btu per ton of product. By 1984, the industry used only 27.7 million Btu per ton--an improvement of 15 percent in 12 years. Over the same time period, the fraction of self-generated fuels (mainly the burning of wood wastes and lignin) increased from 41 percent to 56 percent, an improvement of 36 percent. In consequence, the amount of fossil fuels used to produce a ton of paper product has decreased from 19.2 to 12.2 million Btu, a reduction of over 36 percent.

Process changes have not been major during the period 1972-1984, although some changes have occurred. Thermo-mechanical pulping is the fastest growing pulping process, and continues to substitute for both mechanical pulping and chemical pulping. This substitution has occurred because the thermo-mechanical process yields pulp that is cheaper than the Kraft process, without chemical wastes, and stonger than pulp from the mechanical process. Continuous digesters have been substituted for batch digesters and have nearly supplanted them. Some batch digesters are still purchased, but primarily as emergency capacity to be used during periods of excessive demand or when maintenance is required on the continuous digester. The switch to continuous digesters may slow if a new batch process by Beloit (RDH) becomes widely adopted. One major energy- 
saving feature has been the widespread adoption of computer controls to monitor the quality of the products produced and to meter the use of fuels and other materials. A final set of process changes has been the more effective use of waste heat streams. Blow-heat recuperators, preheaters, vapor recompressors and electric generation facilities have been added or retrofitted to existing equipment to more efficiently use waste heat.

The factors that have contributed to the changing mix of fuels in the pulp and paper industry can be categorized into two major groups. The institutional influences were the passage of the clean air and water acts that forced a change in the operation of pulp and paper mills. The prohibition against discharging chemical or biomass waste streams into rivers required that the plants find a use for these potential energy sources. The clean air act caused the substitution of oil and gas for coal in this industry, as with most other industries in the industrial sector. The economic factors-specifically, higher fuel costs--promoted the more efficient use of biomass as fuel, the increased self-generation of electricity, and the introduction of multi-fueled boilers to allow more rapid fuel switching between oil and gas as relative prices changed.

\section{Chemicals}

Within the chemical industry, four sectors account for 96 percent of all energy use--inorganic chemicals, organic chemicals, agricultural chemicals and plastics and synthetics. In the industrial inorganic industry (SIC 281), two processes account for the bulk of electric energy use, which is 38 percent of total energy consumed--the electrolysis of salt brine to produce chlorine and caustic soda and the separation of natural uranium into fissionable products. Natural gas, the other major fuel used in inorganic chemicals (41 percent), is used to fire small boilers and for direct process heat. In agricultural chemicals (SIC 287), natural gas dominates fuel consumption and accounts for 90 percent of total energy use. That is because ammonia accounts for 87 percent of all agricultural chemicals and its production relies almost exclusively on natural gas for both feedstocks and heating. Some natural gas is also used for miscellaneous materials drying, but 53 percent of total energy consumption is ammonia feedstock, and 37 percent is heat and power for ammonia processing. The other two sectors, industrial organics (SIC 286) and plastic 
materials and synthetics (SIC 282) are interrelated since plastics use much of the organic chemicals produced by SIC 286 . These two sectors account for 95 percent of all petroleum used in the chemical industry, and petroleum accounts for about 65 percent of total energy used in these two sectors. Most of the petroleum is used for feedstocks. All other chemicals--paints, soaps, drugs and miscellaneous chemicals--account for almost 46 percent of the value of Gross National Product originating in this industry, but use only about 5 percent of the energy [Thoreson, Rowberg and Ryan (TRR) 1985].

Energy use in the chemical industry has changed, but not dramatically, since 1972. The use of premium fuels--natural gas and light petroleum end products--has declined from 56 to 45 percent of total use. Energy efficiency has also increased over this period, with best available estimates reckoning this improvement at about 25 percent. But over this same period, there has been a much smaller improvement in the efficiency of use of feedstocks, probably only about five to seven percent. One possible explanation is that feedstocks accounted for a much larger cost share than fuels prior to 1972, so firms were more conscientious about economizing in their use (TRR 1985).

The chemical industry has experienced both rapid growth since the end of World War II and considerable restructuring of the industry. Much in the way of change continues to occur. The importance of the production of bulk chemical commodities continues to decline domestically as petroleum-producing countries add value to basic feedstocks by converting them to bulk chemical commodities abroad. While this sector of the industry has declined, the specialty chemical industry has grown rapidly. This segment is typically located closer to the market and is organized on a much smaller scale. The development of biochemical engineering and the tailoring of specialty catalysts are beginning to affect the costs and energy use of the industry and may provide for dramatic improvements in the future.

\section{Petroleum Refining}

Refining over the last 15 years has been affected by a foreign oil embargo, a doubling of crude petroleum prices twice, and a recent collapse in the world crude oil price to nearly the same level (in real terms) as before the embargo. As a result of the price increases, the way the economy used energy was altered dramatically. Production of refined products declined after 1973 for two 
years, rose again through 1978 , then declined to 15.7 billion barrels per day in 1984--1.6 million barrels a day below the 1973 peak.

Technical, economic and institutional factors have all changed during the period 1972-1984. As resources have been depleted, the heavier and dirtier (i.e., more sulfur content) crudes have replaced the lighter and sweeter crudes. At the same time, the slate of final products produced by refiners has changed in response to market demand and federal environmental regulation. Industry and utilities moved from using residual oil, with a minimum of refining required, to coal and natural gas. As a result of the decline in the demand for resid, the crudes had to be more fully processed. In response to environmental regulations during the same period, lead additives in gasoline to boost octane were replaced with more highly refined oil-based additives. Environmental regulations also limited the amount of sulfur in fuel oils, and its removal requires energy-intensive processes.

These changes, in the absence of efficiency improvements, would have increased energy use in refining. But that has not been the case. Over the period 1972 to 1983, energy use per barrel of processed petroleum is estimated to have decreased about 10 percent. Had the final product slates and the availability of light crudes not changed over time, this efficiency improvement might have been as high as 25 percent.

Refining efficiency improvements have been the result of more effective use of captive fuels and changes in process controls. Still gas, a by-product or residual of refining, and petroleum coke, another by-product but also a premium solid fuel, are the two main sources of self-generated fuels. Together they account for about 62 percent of total fuel use. Natural gas is the dominant purchased fuel, accounting for about 25 percent of total fuel use. Electricity use has increased steadily from about two percent of total fuels use to about five percent, as increased processing of crudes (additiona) pumping), the addition of computer controls, and pollution control equipment have added to electricity requirements.

\subsection{CONCLUSIONS}

At the industry level, there are a number of factors that influence fuel substitution in the industrial sector. Among the factors that have been dis- 
cussed, economic factors are clearly very important. At other times, the institutional and legal requirements imposed by government regulation, particularly pollution abatement requirements, have had a dramatic impact on fuel use. But even these legal requirements can be interpreted as exercising their influence through economic forces--by raising the capital requirement for burning specific fuels, the regulations raise fuel costs indirectiy. Technological factors have also been influential in fuel substitution--e.g., minimills in steel, preheaters and precalciners in cement--but even these developments, it can be argued, were stimulated by the need to economize on a suddenly more expensive input.

At the aggregate level, compositional shifts that give rise to fuel substitution can also be attributed to economic forces. As higher costs are passed along in the form of higher prices, both businesses and ultimate consumers modify their purchase decisions to economize on these more expensive items, shifting product demand from more energy-intensive to less energy-intensive industries. Since these less energy-intensive industries have a different pattern of fuel use than do the more energy-intensive industries, this compositional shift will change fuel use patterns for the industrial sector as a whole.

Economic factors, therefore, appear the most likely major reason for fuel switching in the industrial sector. Technology acts as an enabling mechanism or as a barrier to fuel switching. Institutional factors typicaliy impose constraints or impede the rate at which fuel substitution technology is adopted.

In the next section, the most obvious of these factors--fuel price--is used to explain and then to project fuel shares for the industrial sector and for a selected set of industries. 


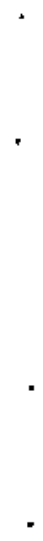

. 


\subsection{PROJECTION OF FUEL SHARES TO 1995}

Using information from the National Energy Accounts, previous sections have provided an overview of historical changes in fuel shares in the industrial sector. In this section a methodology is developed to project changes in fuel shares in the future. The general approach is to use regression analysis to measure the response of fuel shares with respect to changes in relative prices of fuels.

The objective of this portion of the study is to develop a straightforward specification that can reasonably explain the historical evolution of fuel shares by industry. The approach can be described as heuristic, as compared to one that is derived rigorously from economic theory. A more theoreticaliy elegant approach requires significantly more data and estimation effort than could be afforded under the scope of the present study. Section 4.1 describes this approach, Section 4.2 discusses the empirical results, while Section 4.3 provides forecasts of fuel shares. Then Section 4.4 describes in general terms how a more rigorous approach might be followed and, more precisely, why it could not be used here.

\subsection{APPROACH}

Our approach is based on the simple concept that, ceteris paribus, the share of a fuel will fall if its price rises relative to some "average" price for competing fuels. The specification employed is as follows:

$$
s_{i}=a_{i} *\left(P_{i} / P\right) B_{i}
$$

where: $\quad s_{i}=$ share of fuel $i$ to total energy use, in Btu terms,

$$
i=\text { coal, gas, oil, and electricity, }
$$$$
P_{\mathfrak{j}}=\text { price index for fuel } \mathfrak{i} \text {. }
$$

Several formulations were considered or tried in estimating the average price. Perhaps the most appealing approach, from a consistency viewpoint, is that employed by Nyhus and Reimbold (1977) in a study designed to predict import shares by country of origin. This approach defines $P$ implicitly as the price that ensures that the shares add to unity. Thus, in this formulation $\sum a_{j}\left(P_{i} / P\right) B_{i} \equiv 1$. Unfortunately the procedure required to ensure this 
constrafint during estimation is complex and cannot be handled by standard econometric routines.

A second approach involved defining $P$ as an implicit price index, with the weights derived from the actual or predicted shares. To implement this procedure we defined a "composite" competitive price as a weighted average of all the other fuels in the system. For example, in the four fuel system, considered here, we would have for the coal equation:

$$
P=S_{g} * P_{g}+S_{0} * P_{0}+S_{e} * P_{e}
$$

where: $\quad S_{i}=$ share of fuel $i$ in total fuel consumption, $P_{i}=$ price (index) for alternative fuels

In this system the set of weights (shares) are the same for all equations; $P$ will be different in each equation since a different set of fuels is selected.

There are several problems with the definition of $P$ in Equation (2). First, fdeally we desire a system where the shares are functions only of prices and perhaps other variables. This feature is lost if one determines the weights beforehand on the basis of observed shares. Alternatively, in a systems estimation program, the weights can be determined from the predicted shares. However, this approach has the drawback of requiring an extensive amount of computer time and the estimates appear to be quite sensitive to starting values and convergence criteria.

Perhaps a more important drawback, however, is that the set of weights should be optimized with regard to substitution behavior exhibited by the data. Thus, for example, if coal and gas have shown the principal substitution behavior over the time period analyzed, then we would want relatively large weights on both of these fuels. Using the actual or predicted shares as weights will not necessarily pick up this type of pattern.

In light of the above considerations, we then chose to simply estimate a set of parameters to serve as constant weights in the construction of $P$. This approach is the simplest to execute, and over reasonably short time periods, may adequately reflect the substitution potentials. The complete set of equations then becomes: 


$$
\begin{aligned}
& S_{c}=A_{1} *\left[P_{c} /\left(w_{g} * P_{g}+w_{0} * P_{0}+w_{e} * P_{e}\right) /\left(w_{e}+w_{0}+w_{e}\right)\right] B_{1} \\
& S_{g}=A_{2} *\left[P_{g} /\left(w_{c}+P_{c}+w_{0} * P_{0}+w_{e} * P_{e}\right) /\left(w_{e}+w_{0}+w_{c}\right)\right] B_{2} \\
& S_{0}=A_{3} *\left[P_{0} /\left(w_{c} * P_{c}+w_{g} * P_{g}+w_{e} * P_{e}\right) /\left(w_{c}+w_{g}+w_{e}\right)\right] B_{3} \\
& S_{e}=A_{4} *\left[P_{e} /\left(w_{c} * P_{c}+w_{g} * P_{g}+w_{0} * P_{0}\right) /\left(w_{c}+w_{g}+w_{0}\right)\right] B_{4}
\end{aligned}
$$

Note the weights, $w_{j}$, are used only to define relative prices and thus must be subject to a normalization constraint. In the estimation we allowed the weights on gas, oil, and electricity to be freely estimated. The weight on coal was defined as $1-w_{g}-w_{0}-w_{e}$.

\subsection{EMPIRICAL RESULTS}

The system in Equation (3) was estimated for the industrial sector as a whole and for several individual industries. The discussion below first focuses on the aggregate industrial sector results, since this equation will be used to project 1995 fuel shares. Then in Section 4.2.2, results for selected industries are described.

\subsubsection{Results for the Industrial Sector}

Quantity and price data were derived from the National Energy Accounts. Implicit prices were computed from expenditure divided by quantity measured in Btu. Electricity is evaluated at $3412 \mathrm{Btu} / \mathrm{kWh}$; thus fuel shares are defined in terms of delivered Btu.

The estimations were carried out with the maximum likelihood procedure (FIML) in the SORITEC econometric package for the IBM-PC. This procedure takes account of disturbances that may be affecting shares of two or more fuels within a single time period.

The estimation was performed for the period 1971-1981. The use of the full sample period 1958-81 resulted in extremely small price elasticities for all fuels but electricity. Part of the problem stems from the substantial decline in the coal share over the latter half of the 1960s, which cannot be accounted for simply on the basis of fuel price. A very crude attempt to 
account for pollution abatement activity related to coal was made through the use of a dunminy variable, but this technique did not improve the results appreciably. As a result, we decided to restrict the estimation period to the time when the most significant changes in relative fuel prices actually occurred.

The results for the industrial sector estimation are shown in Table 4.1. All parameter estimates are significant at the 5 percent level, given the asymtotic approximation provided by the FIML routine. The price elasticities for gas, $0 i 1$, and electricity enter with negative signs, as anticipated. The price elasticity for coal is positive, although it is not large. Examining the weighting factors for construction of the relative price, coal again is the outlier. The (implied) weight is nearly zero and slightly negative.

\section{TABLE 4.1 Coefficient Estimates for Equation (3) Aggregate Industrial Sector}

\begin{tabular}{lccc} 
Equation & Constant $\left(\mathrm{A}_{j}\right)$ & Elasticity $\left(\mathrm{B}_{i}\right)$ & Weight $(W$ \\
\cline { 2 - 4 } Coal & 0.217 & $(\mathrm{~W})$ \\
& $(103.1)$ & 0.071 & -0.019 \\
Gas & 0.391 & $(5.3)$ & -- \\
& $(89.5)$ & -0.194 & 0.621 \\
$0 i 1$ & 0.243 & $(7.4)$ & $(9.9)$ \\
& $(39.7)$ & -0.293 & 0.211 \\
Electricity & 0.149 & $(6.7)$ & $(6.6)$ \\
& $(126.5)$ & -0.437 & 0.187
\end{tabular}

(a) Asymtotic t-statistics in parentheses

(b) Derived as residual, see text

A look at Figures 4.1 and 4.2 helps to reveal the behavior of the coefficients related to coal. The plot in the top left quadrant of Figure 4.1 shows that there was simply very little variation in coal's share of industrial fuel use for heat and power, in spite of a fairly large drop in its relative price toward the end of the decade. In this particular specification the relative price is a function of estimated parameters. Relative prices defined in this manner are shown in Figure 4.2. Given the small variation in the coal share in the face of the relative price changes shown in Figure 4.2 , the 

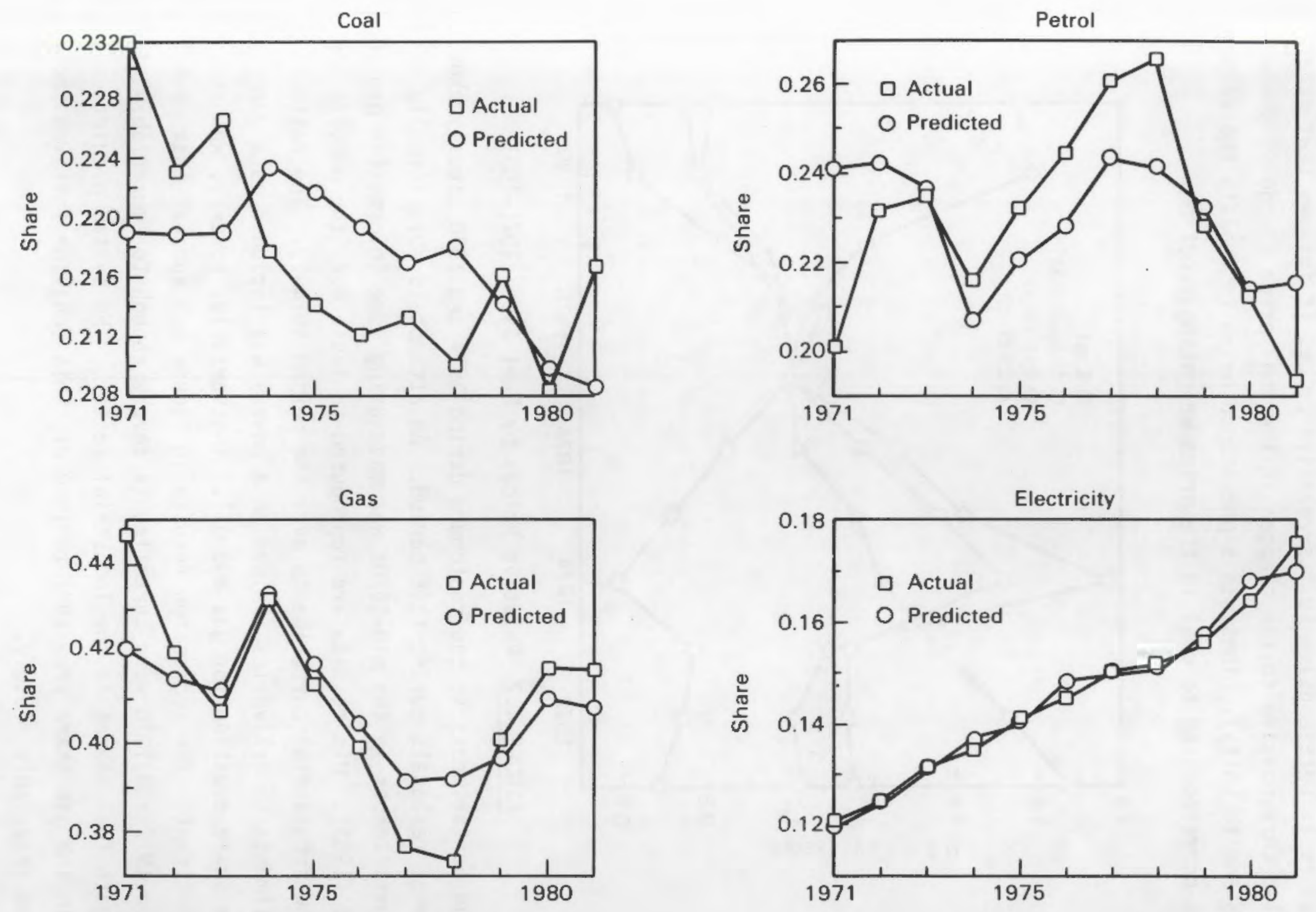

FIGURE 4.1 Predicted and Actual Shares by Fue1, Total Industrial Sector, 1971-1981 
estimated price elasticity necessarily must be near zero. Moreover, since the coal share is unresponsive to its relative price, it follows that other shares are also unresponsive to the changes in the coal price (largely, since all shares add to unity). Thus, this phenonenon helps to explain the very small weight corresponding to coal in the price weighting function.

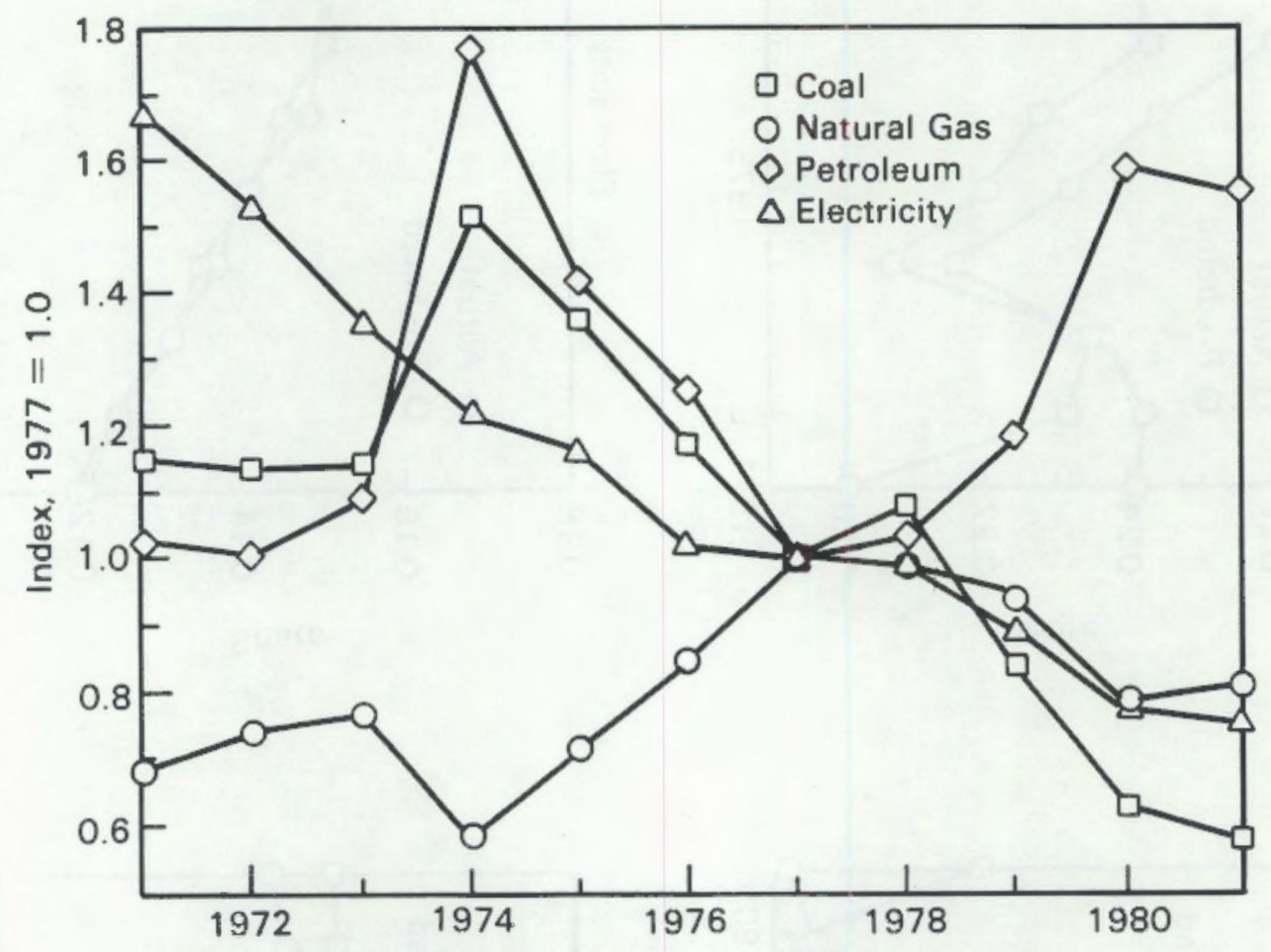

FIGURE 4.2 Relative Prices by Fuel Type, 1971-1981

The curtailments to gas customers during 1977 and 1978 clearly show up in the large residuals during this period. An attempt to more formally account for curtailments in the mid-1970s was made using some information provided by Werbos (1983). His results are reproduced in Table 4.2; the numbers appear to show substantial curtailments over the period 1974-79. The ratio of curtailments to deliveries (raised to a power) was included as a dummy variable in the share equation for gas and oil. The variable, however, was statistically insignificant. The regression results in Figure 4.1 suggest that probably only in 1977 and 1978 were curtailments severe enough to appreciably affect aggregate fuel shares in the industrial sector. The system predicts a large jump in the gas share from 1977 to $1980-81$; this behavior followed the actual pattern reasonably closely. 
TABLE 4.2 Annual Gas Deliveries and Curtailments, U.S. Totals for SIC's 20-39 (Trillion Cubic Feet)

\begin{tabular}{lcc}
$\frac{\text { Year }}{1974}$ & Deliveries & Curtailments \\
\cline { 2 - 3 } 1975 & 2983 & 633 \\
1976 & 2254 & 1034 \\
1977 & 3987 & 1090 \\
1978 & 4349 & 1164 \\
1979 & 4668 & 909 \\
& 5247 & 472
\end{tabular}

Source: Werbos, 1983 (Appendix F., Memorandum on EIA - 50, Table 8.)

The gas curtailment is reflected in the petroleum share plot, again for 1977 and 1978. With the exception of 1981, the movement of relative prices predicts a substantial decline in the oil share in 1979 through 1981. The actual share in 1981 is substantially lower than predicted. This is likely explained by expectations of further increases in prices and problems of availability. With natural gas decontrol beginning to occur, the relative price of oil as measured by the system actually declined in 1981 relative to 1980 .

More puzzling are the large residuals in 1971 in all three of the fossil fuel equations. These may stem from several factors. First, the underprediction for coal may reflect a situation in which environmental constraints were not yet fully binding. Second, industrial gas consumption in 1972 actually fell from 1971 in spite of a rapid economic expansion. The American Gas Association (AGA) quarterly reports for 1972 suggest a significant degree of curtailments for 1972. This development follows a period in which the share of gas rose nearly every year from 1958 forward. Thus, 1971 may actually represent a market more nearly in an equilibrium position, with gas supply meeting demand, than in subsequent years.

The share of total fuel consumption accounted for by electricity grew steadily during the 1970s, following longer term trends. With an estimated price elasticity of -.43 , Equation (3) is able to track this rise in electricity quite wel1, as shown in the lower right portion of Figure 4.1. Note that this specification is able to catch the slowdown that occurred in 1977 and 1978. 


\subsubsection{Results for Selected Industries}

In addition to the aggregate industrial sector, the specification in Equation (3) was estimated for several industries. The results were mixed. Generally, it appears that the specification is too rigid to satisfactorily capture the extent to which specific fuels substituted for each other in specific industries. Results for textiles and cement are discussed below.

Table 4.3 shows the results for textiles. As compared to the aggregate industrial sector, the own price elasticities are all negative and statistically significant. The weight on electricity $(0.761)$ suggests that the shares of the fossil fuels depend primarily on the relationship of their own price to that of electricity. It should be noted, however, that electricity price may be serving as a proxy for other non-energy prices. Thus, electricity should not be interpreted literally as the primary substitute for the fossil fuels.

A pollution abatement dummy variable was included in the equation for coal. Over the estimation period, this variable was assigned values of 0.6 in 1971, 0.8 in 1972, and 1.0 in years thereafter. (In absolute terms, the biggest reductions in coal use came over the period 1967 to 1973. Since much of this decline may have been related to abatement activities, the dummy variable was set at zero for years up to 1967, and then increased linearly to 1973). For textiles, the coefficient was 0.063 and highly significant, measured by a t-statistic of 4.9 .

TABLE 4.3 Coefficient Estimates for Equation (3) Industry-Specific for Textiles

\begin{tabular}{|c|c|c|c|}
\hline Equation & Constant $\left(A_{i}\right)$ & Elasticity $\left(B_{i}\right)$ & Weight $\left(W_{i}\right)$ \\
\hline Coal & $\stackrel{0.188}{(15.6)}(a)$ & $\begin{array}{r}-0.422 \\
(5.4)\end{array}$ & $0.075^{(b)}$ \\
\hline Gas & $\begin{array}{c}0.262 \\
(13.9)\end{array}$ & $\begin{array}{r}-0.260 \\
(7.2)\end{array}$ & $\begin{array}{l}0.086 \\
(1.7)\end{array}$ \\
\hline $0 i 1$ & $\begin{array}{r}0.247 \\
(16.8)\end{array}$ & $\begin{array}{r}-0.286 \\
(3.9)\end{array}$ & $\begin{array}{l}0.078 \\
(1.1)\end{array}$ \\
\hline Electricity & $\begin{array}{c}0.299 \\
(115.1)\end{array}$ & $\begin{array}{r}-0.558 \\
(6.4)\end{array}$ & $\begin{array}{l}0.761 \\
(5.1)\end{array}$ \\
\hline
\end{tabular}

(a) Asymtotic t-statistics in parentheses

(b) Derived as residual, see text 
Although aided by the dummy variable over the 1971-73 period, the estimated equation tracks the shares for coal well over the entire sample period as shown in Figure 4.3. The equation picked up the decline in 1977 and subsequent increases from 1978 through 1981. For electricity, the tracking behavior is equally as good, capturing most of the roughiy 0.08 increase in the share.

The specification unfortunately misses most of the substitution between oil and gas. Several of the observations made for the total industrial sector likely hold here as well, only with stronger force. First, it is 1ikely that gas curtailments were severe in the Southeast during 1975-78, which can account for much of the underprediction in the gas share during this period. Second, the equation predicts a further decline in the gas share even after the sharp rise in oil prices in 1979. Using the equation-generated weights, however, the "relative" price of natural gas actually increases more than oil from 1977 to 1981. Nevertheless, anticipation of future $0 i 1$ price rises and shortages leads firms to shift from oil to gas in 1979 and 1980 . This shift begins to reverse itself by 1981 as reflected in the small decline in the gas share for that year. Although price appears to have played a role in determining fuel shares over this period, these other factors swamped the effect of price. Thus, our simple heuristic approach cannot capture the degree of substitution that actually occurred.

The estimation results for cement are shown in Table 4.4. As described in Section 3.0, the principal fuel substitution in this industry over the 1970s was coal for natural gas. The coefficients for the price aggregation

$$
\begin{aligned}
& \text { TABLE 4.4 Coefficient Estimates for Equation (3) (a) } \\
& \text { Industry-Specific for Hydraulic Cement }
\end{aligned}
$$

\begin{tabular}{lccc} 
Equation & Constant $\left(A_{i}\right)$ & Elasticity $\left(B_{i}\right)$ & $\frac{\text { Weight }\left(W_{i}\right)}{\text { Coal }}$ \\
\cline { 3 - 4 } & 0.601 & -0.37 & 0.415 \\
Gas & $(31.1)$ & $(9.6)$ & -- \\
& 0.239 & -0.675 & 0.751 \\
$0 i 1$ & $(13.2)$ & $(8.0)$ & $(7.3)$ \\
& 0.079 & -0.017 & -0.04 \\
Electricity & $(7.9)$ & $(0.1)$ & $(1.9)$ \\
& 0.073 & -0.525 & -0.126 \\
& $(70.8)$ & $(3.9)$ & $(3.8)$
\end{tabular}

(a) See Table 4.3 for notes. 

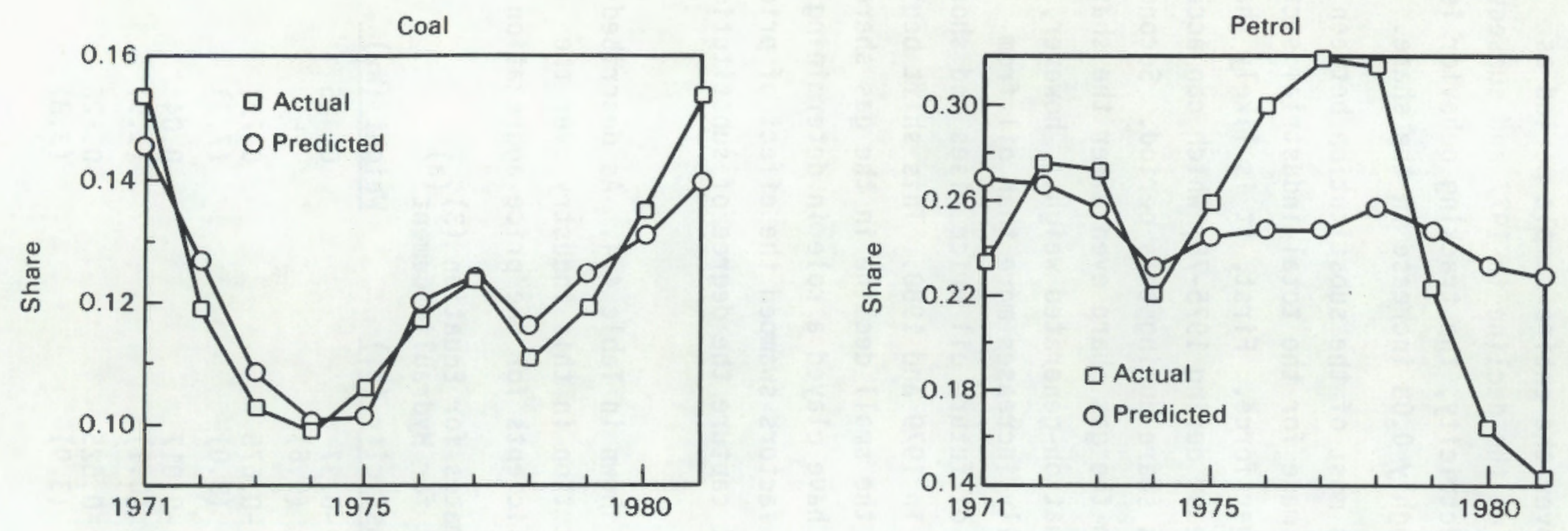

$\stackrel{\rightleftarrows}{\circ}$
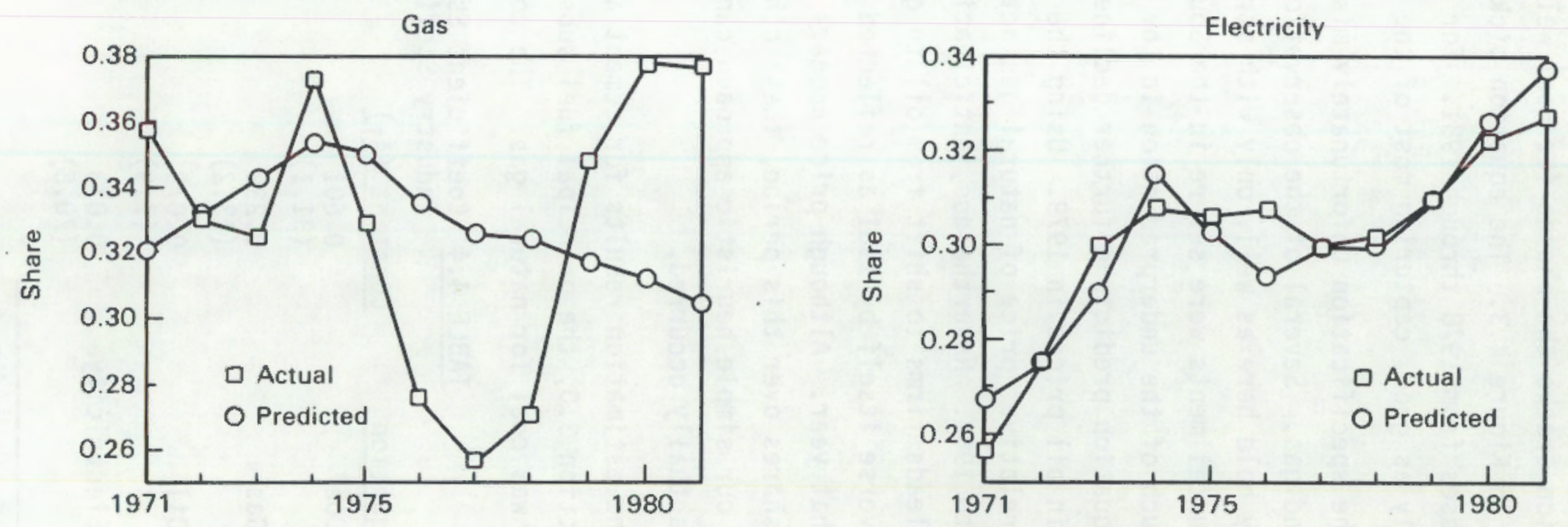

FIGURE 4.3 Predicted and Actual Shares by Fuel for Textiles, 1971-1981 
weights reflect this phenomenon: -0.751 for gas and (an implied) 0.415 for coal. The elasticities for coal and gas are both negative and highly significant.

Figure 4.4 shows that the system captures fairly well the increase in coal at the expense of gas. As in other sectors, the predicted electricity share tracks the historical growth in a reasonable fashion. Unfortunately, the specification does not perform well for petroleum. The extremely small price elasticity translates into an essentially unchanging predicted share. In a system estimation procedure one is essentially attempting to explain the greatest proportion of variance in the shares over all the fuels. Thus, given the fairly inflexible functional form used here, the results indicate that the residual error is minimized in the coal, gas, and electricity equations at the expense of the oil equation. Note, however, the petroleum share is very sma11 relative to coal and gas, falling to 2 percent by 1981 .

\subsection{FUEL SHARES PROJECTIONS}

In this section a "baseline" projection of industrial fuel shares is generated along with several alternative projections. The projections reported in Table 4.5 use Equation (3) as estimated for the entire industrial sector (estimated parameters are shown in Table 4.2, page 4.4).

Projections of fuel shares are dependent on projections of future fuel prices relevant to the industrial sector. Although a number of organizations, both inside and outside DOE, periodically project energy prices, we have restricted our attention to those made by the Energy Information Administration. EIA's latest price projections are presented in the Annual Energy Outlook 1984. Prices for the baseline are taken from EIA's scenario A, "Middle World $0 i 1$ Price/Middle Economic Growth" case. Prices were shown annually to 1990 and then for 1995. The base case will be discussed first, then the alternative scenarios.

\subsubsection{Base Case Projections}

The projected fuel shares are shown in Figure 4.5. Actual shares are shown through 1981. Equation (3) predictions from 1981 through 1995 were scaled on the basis of the forecast error for 1981. In essence, we are modifying the 

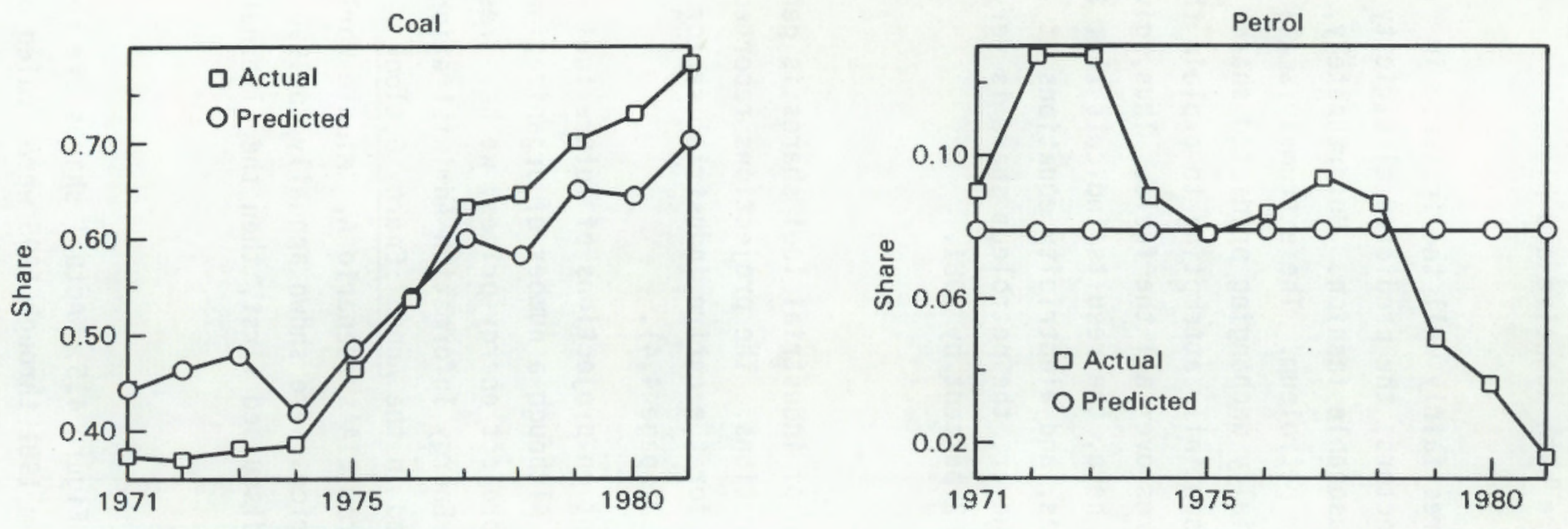

$\stackrel{+}{\sim}$
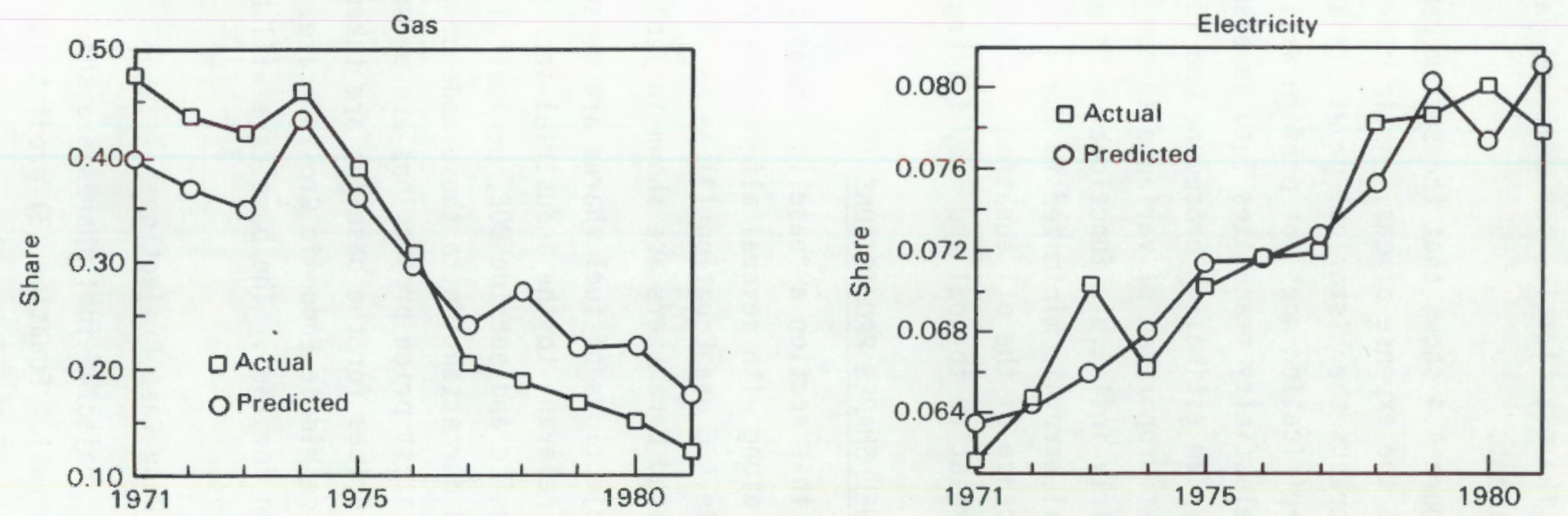

FIGURE 4.4 Predicted and Actual Shares by Fuel for Cement, 1971-1981 
TABLE 4.5 Alternative Price and Fuel Share Projections

$\frac{1990}{\begin{array}{c}\text { Price } \\ \$ 1984 / M M B t u\end{array} \text { Share }}$

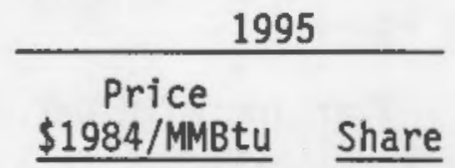

Coal

$\begin{array}{lll}\text { Low } & 2.19 & .217 \\ \text { Base } & 2.19 & .217 \\ \text { High } & 2.18 & .216\end{array}$

2.40

2.40

.215

2.38

.215

216

.214

Gas

$\begin{array}{lll}\text { Low } & 5.25 & .371 \\ \text { Base } & 5.26 & .377 \\ \text { High } & 5.35 & .387\end{array}$

7.02

7.08

.355

7.00

.365

.380

0i1

Low

5.37

.237

.229

$\mathrm{High}$

6.15

7.82

.214

6.22

7.85

10.45

.244

.229

.211

$\frac{\text { Electricity }}{\text { Low }}$

$\begin{array}{lll}\text { Low } & 16.54 & .178 \\ \text { Base } & 16.65 & .179 \\ \text { High } & 16.85 & .183\end{array}$

16.06

16.33

.202

16.40

.210

183

.210

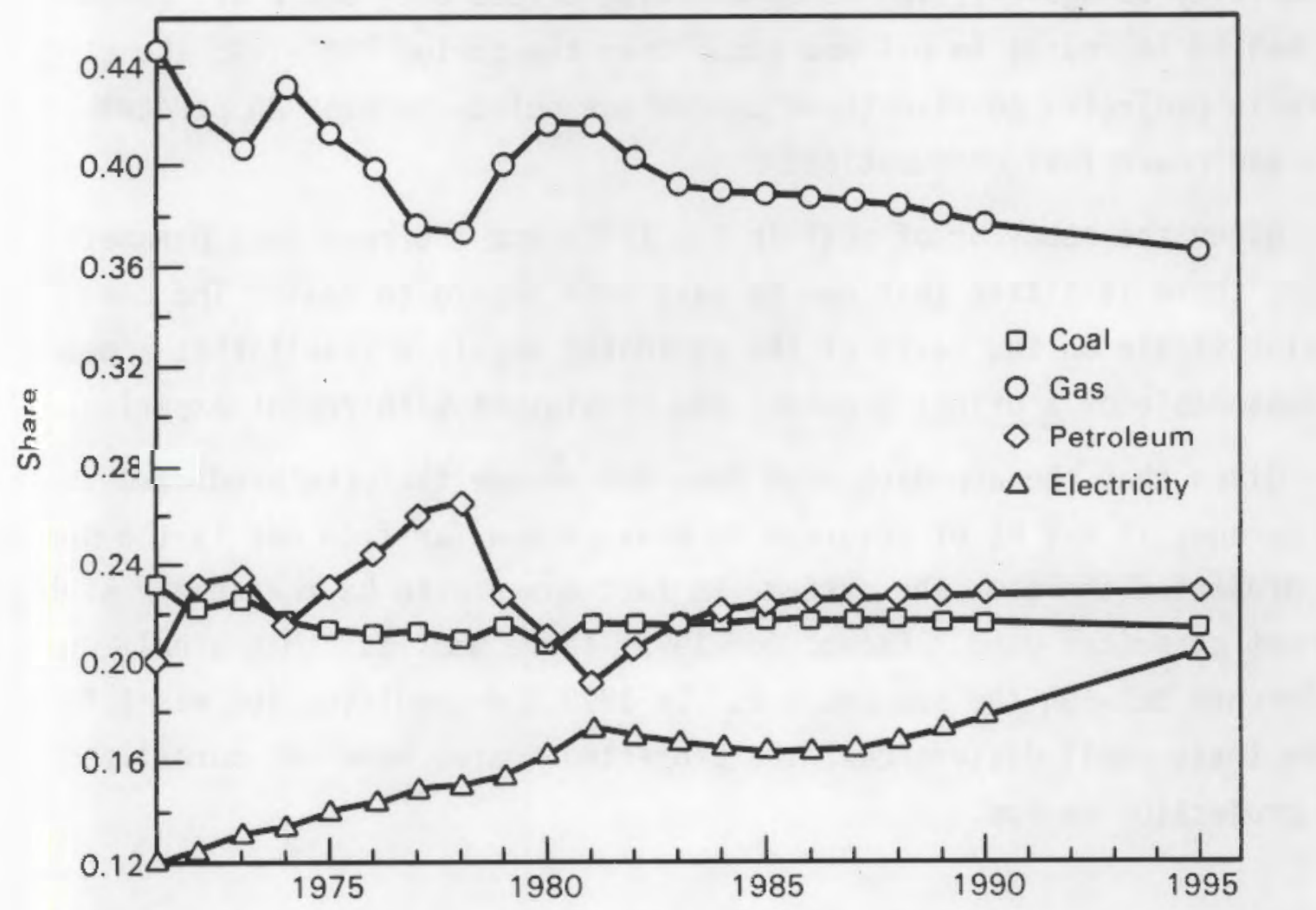

FIGURE 4.5 Baseline Projections of Industrial Sector Fuel Shares 
constant term in the equation so that the 1981 actual and predicted values are equal.

Starting with petroleum, the projection suggests that declining relative oil prices through 1990 will provide a gradual increase in the petroleum share throughout the decade. Much of this shift is "predicted" to have occurred already; the predicted 1984 share is almost back to the 1979 value. Although the timing may be somewhat accelerated, other evidence (Fulkerson and Carlsmith, 1984) suggests that a significant switching back to oil has already occurred.

Somewhat mirroring the pattern for petroleum is the share for natural gas. Real prices for gas under the EIA baseline scenario rise continuously from 1984. By 1991 EIA projects gas prices to rise about 65 percent higher than in 1984, about double the projected rise in petroleum prices. This price differential helps to explain the continued downward trend in the gas share. By 1995 the share is projected to fall about 12 percent relative to 1981 .

Declining prices for fossil fuels as a whole through the mid 1980s serves to actually reduce the electricity share temporarily. By 1995, however, electricity is again rising as electricity prices once again are assumed to lag behind increases in oil and gas. Over the period 1981-1995 the electricity share is projected to rise three percentage points to over 20 percent of the heat and power fuel consumption.

Given the behavior of coal in the 1970s and the resultant parameter estimates, there is little that can be said with regard to coal. The coal share remains stable on the basis of the estimated model, a result that appears to be reasonable on a priori grounds, and consistent with recent experience.

Given that the approach used does not ensure that the predicted shares add to one, it may be of interest to measure how far from one is the sum of the projected shares. The system, in fact appears to be reasonably stable under the set of prices used. Except for 1995, there was less than a half percent difference between the sum and one. In 1995 the predicted sum was 1.014. Given these small differences, the projected shares were not normalized over the projection period. 


\subsubsection{Alternative Projections}

To gauge the sensitivity of the fuel shares to alternative fuel prices, several other simulations were performed. These simulations were based on high and low world oil price projections made by EIA in the 1985 Annual Energy Review. EIA's Case D involves a "low world oil" price projection with a "middle" economic growth case. Case $E$ involves the same underlying economic assumption together with a stronger world oil picture, resulting in higher petroleum prices for the industrial sector.

The results of these simulations are shown in Table 4.5 for 1990 and 1995. The petroleum share, as expected, shows the most variation over the low to high cases. The difference of 0.032 in 1995 is comparable to the behavior of the predicted share over the 1977-1980 period. As appropriate to petroleum's principal substitute, the natural gas share increases by 0.025 between the high and low oil scenarios. Electricity also increases, but to a much more limited extent--less than a percentage point between the extreme scenarios. The coal share is insensitive to the world oil price, owing to the lack of price sensitivity determined for the equation over the estimation period. Realistically, we would expect some of the decline in ofl (in the high price case) to be shared by both gas and coal. Gas, of course, could be expected to account for the bulk of the shift away from fuel oil, as it has in the recent past.

\subsection{ALTERNATIVE APPROACHES BASED ON PRODUCTION THEORY}

The heuristic approach embodied in Equation (3) is straightforward and, as we have seen, provides reasonable in-sample tracking and projections of fuel shares for the aggregate industrial sector. Unfortunately, the results are not entirely satisfactory with regard to coal and thus leave us with a disappointing prediction of how relative fossil fuel prices may affect coal usage in the future. Moreover, the approach presents problems when faced with the more varied substitution behavior observed in particular industries. This section addresses the question of whether a more elaborate specification, based on economic theory, can provide a superior alternative to the approach used in the current study. 
A statistical examination of historical fuel shares can be guided in a number of ways by economic theory. The most general approach envisions firms attempting to minimize the cost of production, given market-determined prices of the factors that they employ. In the early 1970's, theoretical work showed that if producers minimize the cost of producing a given level of output, then the cost function contains all the necessary information to completely characterize the production technology. For analysis of fuel shares, a cost function might be of the general form:

$$
C=f(K, L, M, E, G, O, C)
$$

where:

$$
\begin{aligned}
& K=\text { capital } \\
& L=\text { labor } \\
& M=\text { materials } \\
& E=\text { electricjty } \\
& G=\text { natural gas } \\
& 0=\text { oil } \\
& C=\text { coal }
\end{aligned}
$$

If we specify a particular functional form of the cost function, demand equations for each of the factors can be derived by differentiating the cost function with respect to each of the factor prices. In the past ten to fifteen years, several types of functional forms have been devised to promote empirical analysis of production by economists. A desirable attribute of these functions is that they permit pairs of inputs to show various degrees of substitution or complementary behavior and are "flexible" in the sense that they can approximate any arbitrary production surface.

Although the use of a general cost function is most appealing from a theoretical viewpoint, this approach requires significantly greater effort than that employed in this study. First, a large amount of data is required for implementation. Although the National Energy Accounts provide detailed data on quantity and prices of fuel inputs, a diverse set of sources must be called on to obtain information on nonfuel inputs. The scope of the present project did not allow for the construction of this industry data base.

A second consideration involves the scope of the estimation task, even with data in hand. With available econometric software, a practical limit is simultaneous estimation of four or five equations. Thus, there is the need for a priori collapsing of the number of inputs in Equation (4) (e.g. combining capital and labor, or putting all fossil fuels together, etc.). 
Finally, with the small samples afforded by the available time series, there is critical need to monitor the robustness of the estimation results. Experience in estimation of cost functions in the past has shown that the estimated price elasticities can be quite sensitive to the estimation period or choice of input price (particularity the cost of capital).

The appeal of the general cost function in Equation (4) is that it allows fuel shares to be responsive to non-energy prices and to the level of output. Thus, for example, this general approach would allow for, say, the use of electricity to be more strongly affected by a change in wage rates than fossil fuels would be. Although all fuel shares would change in response to higher wage rates, the distribution among fossil fuels would remain essentially constant.

If we are willing to eschew this generality in the analysis of fuel shares, the problem can be attacked in a more direct manner. More precisely, we can assume that the distribution of fuels is unaffected by non-energy input prices. In formal terms, the cost function in Equation (4) can be written as:

$$
C=f[K, L, M, g(C, E, G, 0)]
$$

where $g$ defines an aggregation function for total energy input.

The cost function approach can still be applied to the aggregate energy bundle, as for the more general approach above. Here, again, a "flexible" functional form can be used to fit the shares of the energy bundle (or energy. cost) by fuel type.

The share function, for a given fuel, would be a function of the relative prices of all competing fuels. For, say, gas, we would have as a general cost

$$
S_{g}=f\left(P_{g} / P_{c}, P_{g} / P_{0}, P_{g} / P_{e}, X\right)
$$

where $\quad S_{g}=$ share of gas of total energy costs, and

$\mathrm{P}_{\mathrm{g}}, \mathrm{P}_{\mathrm{C}}, \mathrm{P}_{\mathrm{O}}, \mathrm{P}_{\mathrm{e}}=$ prices of gas, coal, oil, and electricity, respectively and $X=$ vector of other factors.

The general approach represented by Equation (6) is of course similar to that used in the heuristic approach outlined in Section 4.1. The difference is that in the more general approach we are able to explicitly measure substitution and complenentarity effects between specific fuels. 
Finally, we may be able to pursue an intermediate approach between the full-blown system in Equation (4) and that in Equation (6). This approach would involve collapsing two or more of the non-energy factors. Thus, we might be able to construct a single price for "value added," comprising both capital and labor. In such a system we would model the energy-output ratios explicity, rather than the cost shares. Using gas as an example again, the general functional form thus would be:

$$
E_{g} / Q=f\left(P_{g} / P_{v}, P_{s} / P_{0}, P_{g} / P_{c}, P_{g} / P_{e}, X\right)
$$

This approach has the advantage of explaining fuel shares on the basis of differential "energy productivity" effects by fuel as well as explicit substitution of fuels. When derived from a cost function, constraints can be placed on the price coefficients to reduce the number of independent parameters that must be estimated. Essentialiy, this means that the effect on gas from a rise in the oil price is mirrored by a similar effect on oil should the price of gas rise. This "symmetry" is one of the key advantages of deriving the system from a specific cost function. 


\subsection{CONCLUSIONS AND RECOMMENDATIONS}

This section draws together the threads of the descriptive analysis of industrial sector fuel share movements, the discussion of factors that might account for fuel substitution, and the experience of empirically estimating relationships between fuel prices and fuel shares. Section 5.1 organizes the finding of these previous sections into a set of conclusions. Section 5.2 then articulates a set of recommendations that would allow more detailed projections of fuel shares in the industrial sector.

\subsection{CONCLUSIONS}

The evidence since 1958 bears out the fact that fuel shares have changed, in some instances dramatically, and that complex phenomena are at work that cannot be fully explained by economic factors such as fuel prices. But from both an empirical and a theoretical perspective, fuel prices have a significant impact on fuel substitution in the industrial sector. The results of the descriptive analysis of the historical pattern of fuel shares, on which this broad conclusion is based, suggests the following observations.

During the late 1960s and early 1970s, 011 and gas supplanted much of the use of coal in the industrial sector as a whole. But this substitution was already under way before any expectation of environmental regulations could have become evident. Technological considerations can partly explain this, but a full explanation would require an examination of the availability of coal, the penetration of natural gas and oil technologies, and other factors even prior to 1958.

Electrification is an ongoing and continuing trend in the industrial sector that cannot be explained adequately by readily accessible economic evidence. Anecdotal evidence--for example, the shift from the wet to the dry process in cement--suggests that the penetration of electricity as a fuel is probably a misrepresentation. $0 i 1$, gas, and coal, under specific industry conditions, clearly can and have substituted for one another. But the only evident case of electricity substituting for another fuel revealed in the historical descriptions of fuel shares, in primary aluminum, was revealed not to have occurred. 
Since the early 1970s, oil and gas appear to be the two fuels that can readily be substituted; moveover, the industrial sector does so. Although recent evidence is confused by many disruptions to the market mechanisms on which the effective translation of economic cause to fuel-substitution effect depends, economic forces (in the form of relative prices) are clearly at work.

Despite these confounding factors, the projection exercise of Section 4.0 suggests that relative prices capture enough of these economic forces to provide a crude tool for projecting fuel shares in the industrial sector. Based on this tool and EIA assumptions about fuel price increases, oil shares are expected to return to 1979 levels by the mid-1990s.

Any analyst would feel uncomfortable putting a great deal of faith in these forecasts. Apart from the inherent problems associated with forecasting, the projection tool does not elicit overconfidence in its use, based on applications at the industry level. Accordingly, the following recommendations are made with the expectation that they would result in a better projection tool.

\subsection{RECOMMENDATIONS}

The complexity of the substitution phenomena requires a more sophisticated approach than the current effort has allowed. In this final section, a number of different approaches are sketched out, each of diminishing sophistication, that would provide empirical projections of fuel shares for the industrial sector. These are all advanced as options, but resource constraints will likely make the choice obvious.

In line with the argument in Section 4.4 , the most complete system begins with the production relationship shown in Equation (4). By specifying a functional form, say a symmetric generalized Barnett (Diewert and Wales, 1985), the factor demand equations could be determined by differentiation with respect to each of the arguments in the cost function. This would yield seven equations with about 40 parameters subject to restrictions on sets of those parameters --i.e., some add to one, others add to zero. Even with no potential for adjustment over time, this system of equations is quite large. When dynamic adjustment is considered, the number of parameters increases even more. Although 
large, this approach would allow for the interaction of fuels with different, non-energy factors of production such as labor and other materials. With the exception of materials, the data to estimate this sort of function are currently available. Intermediate materials, although not currently available, are scheduled for publication by the end of the current calendar year. This approach is both the most theoretically satisfying and the most costly.

At a slightly lower level of sophistication, but more tractable from both a computational point of view and because of data availability, is the approach suggested by Equation (7) of Section 4.4. Pindyck (1979) uses such an approach for several countries, combining time-series and cross-sectional data. His approach drops the non-energy material input, since information is not readily available for most of the countries in his sample. As in the previous case, this could be treated at either a dynamic or static level, with somewhat more computational burden imposed by the dynamic formulation. Data are currently available to undertake this estimation, although not organized for this task, but the estimation system may have to be upgraded beyond current capabilities.

A final recommendation collapses all other non-energy factors of production into a single element--value added--then adds this to the system described in Equation (5) of Section 4.4. This would add only a single additional equation, but would allow for the substitution between energy and non-energy inputs. As with the other specifications, both dynamic and static formulations could be attempted. 


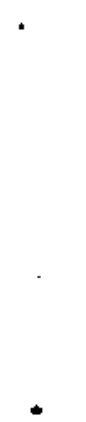

.

.

\author{
.
}




\section{REFERENCES}

Basta, N. 1986. "New Life for Steel," High Technology. April: 46-52.

Diewert, W. E. and T. J. Wales. 1985. "Flexible Functional Forms and Global Curvature Conditions," Discussion Paper No. 85-19. University of British Columbia, Vancover, Canada.

Energetics, Inc. 1986. Communications.

Faucett, Jack, Associates. 1984. National Energy Accounts. JACKFAU-84-316. Chevy Chase, Maryland.

Garrett-Price, B. A. 1985. Potential for Energy Conservation in the Cement Industry. PNL-5330. Pacific Northwest Laboratory, Richland, Washington.

MacAvoy, P. W. 1983. Energy Policy: An Economic Analysis. W. W. Norton and Company, New York.

Nyhus, D. and T. C. Reimbold. 1977. "A Dynamic World Regional Input-Output Model." In Medium-Term Dynamic Forecasting: the 1975 London Input-Output Conference. Input-0utput Publishing, London.

Office of Technology Assessment. 1983. Industrial Energy Use. OTA-E-198. Congress of the United States, Washington, D. C.

Pindyck, Robert S. 1979. "Interfuel Substitution and the Industrial Demand for Energy: An International Comparison, " Review of Economics and Statistics. LXI (2), pp. 169-179.

Portland Cement Association. 1975. Energy Conservation Potential in the Cement Industry. FEA/D-75/400. Federal Energy Administration. Washington, D. C.

Portland Cement Association. 1983. U. S. and Canadian Portland Cement Industry: Plant Information Summary. Market and Economic Research Department, Skokie, Illinois.

Portland Cement Association. 1984. The U. S. Cement Industry: An Economic Report. Third Edition--January, $1 \overline{984 . ~ S k o k i e, ~ I l l i n o i s . ~}$

Reister, D. B. and W. D. Devine, Jr. 1981. "Total Costs of Energy Services," Energy 6(4), pp. 305-315.

Reister, D. B., J. A. Edmonds and R. W. Barnes, 1982. THE OAK RIDGE INDUSTRIAL MODEL: Volume II--Model Description. Oak Ridge National Laboratory, Oak Ridge, Tennessee.

Thoreson, R., R. E. Rowberg and J. F. Ryan. 1985. "Industrial Fuel Use: Structure and Trends," Annual Energy Review. 10: 165-199. 
U. S. Department of Commerce, Bureau of Census, 1980. 1977 Census of Manufactures: Fuels and Electric Energy Consumed. MC77-SR-4. Washington, D. C.

U. S. Department of Commerce, Office of Business Analysis. 1985. The U.S. Primary Iron and Steel Industry Since 1958. Washington, D. C.

U. S. Department of Commerce. 1981. 1979 Annual Survey of Manufactures: Fuels and Electric Energy Consumed. M79(AS)-4.1. Washington, D. C.

U. S. Department of Energy. 1980. The Industrial Energy Efficiency Improvement Program. DOE/CE-0015. Washington, D. C.

U. S. Department of Energy, Energy Information Agency. 1984. State Energy Data Report. DOE/EIA-0214(82). Washington, D. C.

U. S. Department of Energy, Energy Information Agency. 1985. Annual Energy Review. DOE/EIA-0384(84). Washington, D. C.

U. S. Department of Energy, Office of Policy, Planning and Analysis. 1983. An Assessment of Factors Affecting Industrial Electricity Demand. DOE/PC/ 70039-1. Washington, D. C.

U. S. Department of the Interior, Bureau of Mines. 1984/1974. "Cement." Minerals Yearbook, 1982 (1972). Washington, D. C.

Werbos, Paul J. 1983. Documentation of the PURHAPS Industrial Demand Model: Volume II Data Base Description. D0E/EIA-0420/2. Energy İnformation Agency, U. S. Department of Energy. Washington, D. C. 
PNL -5796

UC-98

\section{DISTRIBUTION}

No. of

Copies

\section{OFFSITE}

Lynda T. Carlson

Director of Energy End Use

U.S. Department of Energy

Energy Information Administration

Mai 1 Stop EI-65

Forrestal Building

1000 Independence Avenue S.W.

Washington, DC 20585

John Corliss

U.S. Department of Energy

Policy, Safety and Environment

Mail Stop PE-33

Forrestal Building

1000 Independence Avenue S.W.

Washington, DC 20585

Bruce Cranford

office of Planning \& Environment

U.S. Department of Energy

Mail Stop FE-13

Germantown, MD 20545

Harvey Major

Office of Conservation

U.S. Department of Energy

Mail Stop CE-12

1000 Independence Avenue, S.W.

Washington, D.C. 20585

Ken Friedman

Office of Conservation

U.S. Department of Energy

Mail Stop CE-12

1000 Independence Avenue, S.W.

Washington, D.C. 20585
No. of

Copies

OFFSITE

Robert Wend1ing

Office of Business Analysis

Room 4527

Main Commerce Building

Department of Commerce

Washington, DC 20543

Paul Werbos, Lead Analyst Industrial Energy Demand Energy Information Admin. Mail Stop EI-621

Forrestal Building 1000 Independence Avenue S.W. Washington, DC 20585

William B. Williams, Director Office of Industrial Programs U.S. Department of Energy Ma11 Stop CE-12

Forrestal Building 1000 Independence Avenue S.W. Washington, D.C. 20585

Peggy Podolak office of Policy Integration U.S. Department of Energy

Forrestal Building, MAIL STOP PE-40 1000 Independence Avenue, S.W. Washington, D.C. 20585

Vito Stagliano

Office of Policy Integration U.S. Department of Energy

Forrestal Building, MAIL STOP PE-40 1000 Independence Avenue, S.W. Washington, D.C. 20585 


\section{Distribution}

No. of

Copies

\section{OFFSITE}

Robert C. Marlay

Office of Energy Research

Mail Stop ER-30, F-331

U.S. Department of Energy

Washington, D.C. 20545

Massoud Jourabchi

Massachusetts Executive Office of Energy Resources

Room 1500

100 Cambridge Street

Boston, MA 02202

30 DOE Technical Information Center
No. of

Copies

OFFSITE

\section{ONS ITE}

DOE Richland Operations office

J. J. Sutey

40 Pacific Northwest Laboratory

R. C. Adams

W. B. Ashton

D. B. Belzer

J. W. Currie

R. J. Moe

J. M. Roop (25)

Economics Library (3)

Publishing Coordination (2)

Technical Information Center (5) 